\title{
LUT
}

University

\section{Removal of pharmaceutically active compounds (PhACs) from real membrane bioreactor (MBR) effluents by photocatalytic degradation using composite Ag2O/P-25 photocatalyst}

\author{
Gurung Khum, Ncibi Mohamed Chaker, Thangaraj Senthil K., Jänis Janne, \\ Seyedsalehi Mahdi, Sillanpää Mika
}

This is a Author's accepted manuscript (AAM) version of a publication published by Elsevier

in Separation and Purification Technology

DOI: $10.1016 / j . s e p p u r .2018 .12 .069$

Copyright of the original publication: (C) 2018 Elsevier B.V.

Please cite the publication as follows:

K. Gurung, M. Chaker Ncibi, S.K. Thangaraj, J. Jänis, M. Seyedsalehi, M. Sillanpää, Removal of pharmaceutically active compounds (PhACs) from real membrane bioreactor (MBR) effluents by photocatalytic degradation using composite Ag2O /P-25 photocatalyst, Separation and Purification Technology (2018), doi: https://doi.org/10.1016/j.seppur.2018.12.069

This is a parallel published version of an original publication. This version can differ from the original published article. 


\section{Accepted Manuscript}

Removal of pharmaceutically active compounds (PhACs) from real membrane bioreactor (MBR) effluents by photocatalytic degradation using composite $\mathrm{Ag}_{2} \mathrm{O} / \mathrm{P}-25$ photocatalyst

Khum Gurung, Mohamed Chaker Ncibi, Senthil K. Thangaraj, Janne Jänis, Mahdi Seyedsalehi, Mika Sillanpä ä

PII: S1383-5866(18)33715-8

DOI: https://doi.org/10.1016/j.seppur.2018.12.069

Reference: SEPPUR 15211

To appear in: Separation and Purification Technology

Received Date: $\quad 22$ October 2018

Revised Date: $\quad 24$ December 2018

Accepted Date: $\quad 25$ December 2018

Please cite this article as: K. Gurung, M. Chaker Ncibi, S.K. Thangaraj, J. Jänis, M. Seyedsalehi, M. Sillanpää, Removal of pharmaceutically active compounds (PhACs) from real membrane bioreactor (MBR) effluents by photocatalytic degradation using composite $\mathrm{Ag}_{2} \mathrm{O} / \mathrm{P}-25$ photocatalyst, Separation and Purification Technology (2018), doi: https://doi.org/10.1016/j.seppur.2018.12.069

This is a PDF file of an unedited manuscript that has been accepted for publication. As a service to our customers we are providing this early version of the manuscript. The manuscript will undergo copyediting, typesetting, and review of the resulting proof before it is published in its final form. Please note that during the production process errors may be discovered which could affect the content, and all legal disclaimers that apply to the journal pertain. 


\section{Removal of pharmaceutically active compounds (PhACs) from real membrane bioreactor (MBR) effluents by photocatalytic degradation using composite $\mathrm{Ag}_{2} \mathrm{O} / \mathrm{P}-25$ photocatalyst}

Khum Gurung a*, Mohamed Chaker Ncibi a, Senthil K. Thangaraj ${ }^{b}$, Janne Jänis ${ }^{b}$, Mahdi Seyedsalehi c , Mika Sillanpää a

aDepartment of Green Chemistry, School of Engineering Science, Lappeenranta University of Technology, Sammonkatu 12, FI-50130 Mikkeli, Finland.

bDepartment of Chemistry, University of Eastern Finland, Yliopistonkatu 7, FI-80101, Joensuu, Finland.

cSchool of Environment, Tsinghua University, Beijing 100084, China.

${ }^{*}$ Corresponding author. Phone: +358 409320496

E-mail: khumgrg@yahoo.com; mika.sillanpaa@lut.fi 


\section{Abstract}

Pharmaceutically active compounds (PhACs) are emerging pollutants causing serious challenges to wastewater treatment plants due to poor biodegradability. In this study, the enhanced removal of highly recalcitrant and commonly monitored PhACs, carbamazepine (CBZ) and diclofenac (DCF) by heterogeneous photocatalysis was investigated using 5\% $\mathrm{Ag}_{2} \mathrm{O} / \mathrm{P}-25$ photocatalyst. The photocatalyst was characterized by scanning electron microscope (SEM-EDX), Brunauer-Emmett-Teller (BET), and UVvis diffuse reflectance spectra (UV-DRS). The effects of catalyst dose, initial pollutants concentration, and mineralization during the photocatalytic degradation of PhACs were investigated. The matrix effect was assessed in deionized water (DW) and real membrane bioreactor effluent (RME). Optimal CBZ and DCF removals of $89.10 \%$ and $93.5 \%$, respectively for $180 \mathrm{~min}$ of UV irradiation were achieved at catalyst dosage of $0.4 \mathrm{~g} \mathrm{~L}^{-1}$ in DW matrix. However, the optimal catalyst dosages for CBZ and DCF in RME matrix were increased by factor 2 and 1.5, respectively, to achieve the same degree of removal. Declining trends of removal rate were observed when initial concentrations of both the PhACs were increased under optimal catalyst dosages, and kinetics seem to fit the Langmuir-Hinshelwood model. Photo-induced holes and $\cdot \mathrm{OH}$ were the dominant oxidation species involved in the photocatalytic degradation of the PhACs. A plausible reusability of 5\% Ag20 /P-25 photocatalyst was observed for both the PhACs. Moreover, various aromatic/aliphatic intermediates generated during the photodegradation CBZ were identified using fourier-transform ion cyclotron resonance (FT-ICR) mass spectrometry, and a possible multi-step degradation pathway was proposed. Overall, the removal of PhACs using 5\% $\mathrm{Ag}_{2} \mathrm{O} / \mathrm{P}-25$ photocatalyst showed promising results in real wastewater. 
Keywords: PhACs; photocatalytic degradation, $\mathrm{Ag}_{2} \mathrm{O} / \mathrm{P}-25$ photocatalysts; matrix effect; transformation products 


\section{Introduction}

Pharmaceutically active compounds are used for the prevention, diagnosis, and treatment of several diseases in humans and animals. The global annual average per capita consumption of pharmaceuticals is estimated at about $15 \mathrm{~g}$, whereas industrialized countries accounted between 50 and $150 \mathrm{~g}$ [1]. The annual per capita expenditures on pharmaceutical ranged from US\$ 7.61 in low-income countries to US\$ 431.6 in high-income countries [2]. As most of the PhACs are non-volatile and often charged molecules composed of diverse moieties, these emerging pollutants are highly recalcitrant and not entirely degraded after the medical use, hence the excretion of unchanged (parent) compounds and metabolites and their channeling to the aquatic environment [3]. In recent years, the fate of the PhACs and their metabolites has received a great deal of interest from the scientific community. Though PhACs are normally detected in the concentration range of $n g \mathrm{~L}^{-1}$ or ?g $\mathrm{L}^{-1}$, they can pose serious issues due to their potential adverse effects on human health and ecosystem $[4,5]$. However, other factors such as increased persistence, time of exposure, biotransformation, and degradation mechanisms can also influence the impacts of PhACs, other than their concentration alone [5]. Among the large number of PhACs, CBZ and DCF are the most frequently identified in aquatic environments [1].

CBZ is an antiepileptic drug often used to treat epilepsy and seizures, whereas DCF is a non-steroidal anti-inflammatory drug (NSAID) commonly used as analgesic, antirheumatic, and antiarthritic [6,7]. CBZ has been proposed as an anthropogenic indicator in water bodies [8]. Moreover, DCF is included in the watch list of priority substances as emerging pollutants in EU directive that needs careful environmental monitoring in its member states [9]. 
The wastewater treatment plants (WWTPs) are the primary receptor of PhACs via direct and unsafe discharge of untreated wastewaters from domestic households, industries, agriculture lands, and hospitals [10,11]. PhACs have been found in the effluents of municipal WWTPs because of their incomplete removal [5]. It is well known that conventional WWTPs are not fully efficient in treating most of the PhACs $[1,12,13]$. Even Membrane bioreactors (MBRs), which are regarded as having superior capabilities in terms of performance and flexibility [14], are not effective in the removal of certain PhACs $[8,15]$. In this regard, many researchers have recommended the development of treatment systems where biological degradation is integrated with advanced oxidation processes (AOPs) as a pre-treatment of effluents, in order to improve biodegradability and overall removal efficiency of PhACs, before their discharge into water bodies $[4,16]$. Despite their cost, the use of AOPs is still justified as complete degradation of persistent pollutants is not always needed [4]. The prospective application of various methods such as Fenton oxidation $[17,18]$, ozonation [19], chemical oxidation [20], and $\mathrm{TiO}_{2}$ photocatalysis [7] processes have been proposed to transform PhACs into non-toxic and biologically inactive compounds.

$\mathrm{TiO}_{2}$ is the most commonly used photocatalyst ( $E_{G}=3.2 \mathrm{eV}$ ) because of its cost, and remarkably active and stable features $[7,21,22]$. Heterogeneous $\mathrm{UV} / \mathrm{TiO}_{2}$ photocatalysis has become the most attractive AOP to remove varieties of organic pollutants from water and wastewater [16]. In heterogeneous $\mathrm{UV} / \mathrm{TiO}_{2}$ photocatalysis, upon irradiation of $\mathrm{TiO}_{2}$ semiconductor by UV -vis light, an electron (e $\mathrm{e}^{-}$) is promoted to the conduction band and a hole $\left(h^{+}\right)$is generated on the valence band site vacated by the electron, thereby forming highly reactive oxygen species (ROS) such as hydroxyl $\left({ }^{\bullet} \mathrm{OH}\right)$ and superoxide $\left(\bullet^{-}\right)$radicals $[21,23-25]$. Therefore, heterogeneous photocatalysis is 
based on the chemistry of photo-generated $h^{+}$and/or the ${ }^{\bullet} \mathrm{OH}$, which promotes nonselective oxidation of pollutants $[3,26]$. Yet, there are some drawbacks associated with conventional $\mathrm{TiO}_{2}$ such as rapid recombination of charge carriers $\left(\mathrm{e}_{\mathrm{cb}}{ }^{-} / h_{\mathrm{vb}}{ }^{+}\right)$, difficulty in separating the reacted $\mathrm{TiO}_{2}$ particles, inefficient quantum yield, and wide energy band gap, hindering its industrial applications $[4,7,27]$. Therefore, several R\&D studies focused on developing highly efficient UV-vis light driven photocatalysts by doping $\mathrm{TiO}_{2}$ with narrow band gap semiconductors, which is crucial having less energy use and highly efficient photocatalytic oxidation of pollutants $[27,28]$.

Many studies have suggested that fine particles of transition metals or their oxides dispersed on the surface of photocatalyst matrix could act as electron traps, which effectively reduces the combination of charge carriers and improves photocatalytic activity $[22,29,30]$. $\mathrm{Ag}_{2} \mathrm{O}$ nanoparticles doped on $\mathrm{TiO}_{2}$ particles can enhance the optical absorption spectrum and lattice structural stability of $\mathrm{TiO}_{2}$, improving photocatalytic degradation of hazardous pollutants under UV-vis light irradiation [21,23,31]. Indeed, $\mathrm{Ag}_{2} \mathrm{O}$ is a proven photocatalyst for the degradation of organic pollutants under visible light irradiation having a narrow band gap of $1.2 \mathrm{eV}$ [32]. The physicochemical changes in the $\mathrm{TiO}_{2}$ particles after doping, such as increasing surface area, decrease of $\mathrm{TiO}_{2}$ crystals, and homogeneity in particles surface size, are responsible for the enhancement of photocatalytic efficacy [4,33]. Additionally, recovery and reusability of $\mathrm{TiO}_{2}$ can be enhanced due to improved segregative specialty with impurity doping [30]. The photocatalytic efficiency of $\mathrm{Ag}_{2} \mathrm{O}$ doped $\mathrm{TiO}_{2}$ has been well confirmed by nitrate reduction [34] and degradation of organic dyes [28,30,35]. Nevertheless, to the best of our knowledge, the application of $\mathrm{Ag}_{2} \mathrm{O}$ doped $\mathrm{TiO}_{2}$ (P-25) nano-particles in 
photocatalytic degradation of CBZ and DCF from real MBR effluent has not been studied so far.

The main objective of this study was to investigate the removal of commonly used PhACs including CBZ and DCF from two aqueous matrices, i.e. DW and RME, by heterogeneous photocatalytic degradation using $\mathrm{Ag}_{2} \mathrm{O} / \mathrm{P}-25$ photocatalyst. The composite heterojunction $5 \% \mathrm{Ag}_{2} \mathrm{O} / \mathrm{P}-25$ photocatalyst was synthesized by a simple $\mathrm{pH}$ mediated chemical precipitation reaction method and its photocatalytic efficiency for the removal of PhACs from both matrices were examined. The emphasis was given on the influence of catalyst dose and mineralization in both DW and RME, the effect of initial pollutants concentration, stability of catalyst, and determination of reactive oxygen species and reaction mechanism. Moreover, various intermediate products formed during the photodegradation of CBZ were identified, and a possible multi-step degradation pathway was proposed.

\section{Materials and methods}

\section{$2.1 \quad$ Chemicals}

All the chemicals used were analytical grade and purchased from Sigma-Aldrich Chemical Co. (St. Louis, USA), unless specified. The chemicals used for this experiment include CBZ ( $\geq 99 \%$, meets USP testing specifications), DCF (2-[(2,6-dichlorophenyl) amino]benzeneacetic acid sodium salt), Aeroxide ${ }^{\circledR}$ P-25 as commercial $\mathrm{TiO}_{2}(21 \mathrm{~nm}$ primary size (TEM), $\geq 99.5 \%$ trace metal basis), $\mathrm{AgNO}_{3}$ ( $99.999 \%$ trace metal basis), $\mathrm{NaOH}$ ( $\geq 98 \%$, anhydrous), Acetic acid (natural, $\geq 99.5 \%$ ), N,N Dimethylformamide (anhydrous,99.8\%), Lithium acetate dehydrate (99.999\% trace metal basis), Titanium(IV) butoxide (reagent grade,97\%), Palladium(II) chloride ( $\geq 99.9 \%)$, 
Hydrochloric acid (reagent grade, $37 \%$ ), Tin (II) chloride dehydrate ( $\geq 99.99 \%$ trace metal basis), Sodium citrate tribasic dehydrate (ACS reagent, $\geq 99.0 \%$ ), Nickel nitrate ( 99.999\% trace metal basis), Methanol ( $\geq 99.8 \%$, anhydrous), and Ethylenediaminetetraacetic acid sodium salt dehydrate (EP reference standard).

\subsection{Synthesis of photocatalysts}

$5 \%(\mathrm{w} / \mathrm{w}) \mathrm{Ag}_{2} \mathrm{O} / \mathrm{P}-25$ photocatalysts were synthesized via a simple $\mathrm{pH}-\mathrm{mediated}$ chemical precipitation reaction method [34]. The procedure typically includes the dispersion of $1.0 \mathrm{~g}$ of P-25 in $117 \mathrm{~mL}$ of deionized water and the solution was stirred for 4 h. Subsequently, 540 ? $2 \mathrm{~L}$ of $0.2 \mathrm{M} \mathrm{AgNO}_{3}$ solution was added dropwise into the suspension. The mixture was then stirred in dark for $30 \mathrm{~min}$ in order to reach $\mathrm{Ag}^{+}$ sorption equilibrium. Then, a measured amount of $0.1 \mathrm{M} \mathrm{NaOH}$ solution was slowly added into the $\mathrm{Ag}^{+}$pre-equilibrated mixture and stirred for $1 \mathrm{~h}$ at room temperature. The mixture was filtered through 0.45 ?m nylon membranes (VWR, USA) and washed repeatedly with deionized water and ethanol. The obtained pallets were then kept in deep-freezer for $24 \mathrm{~h}$ and lyophilized. After grinding and sieving through 500 ? sieve, the dried powder was used for subsequent experiments.

Furthermore, three other photocatalysts were also synthesized by adopting the methods from literatures including $\mathrm{Sn}_{3} \mathrm{O}_{4} / \mathrm{P}-25$ [33], PdO/P-25 [34], and NiO/P-25 [35] by doping different metallic substrates over pure P-25.

\subsection{Model solutions and matrix}

Model solutions containing target PhACs (CBZ and DCF) in two different matrices were adopted for this study. The properties of target pollutants in this study are shown in

Table 1. The aqueous solution matrices were prepared by spiking CBZ or DCF in 
deionized (ultrapure Milli-Q) water and in real effluent of the submerged MBR pilot plant located in Kenkäveronniemi WWTP (Mikkeli, Finland). The detailed descriptions of MBR pilot plant and operating conditions are described in our previous studies $[10,15]$. The main physicochemical characteristics of the MBR effluent are listed in Table S1 (Supplementary information)

Table 1 (Here)

\subsection{Characterization of photocatalysts}

Microstructure and morphology of the synthesized photocatalysts were examined by scanning electron microscope (SEM) (Hitachi, SU3500, Japan) using acceleration voltage of $5 \mathrm{kV}$. The elemental analysis of photocatlyst was performed using energydispersive X-ray spectroscope (Thermo Fisher,USA). The Brunauer-Emmett-Teller (BET) surface area (SBET) was determined by using Tristar II Plus. The UV-vis diffuse reflectance spectra were measured in the range of 250-800 nm using Agilent Cary 5000 spectrophotometer with DRA2500 integrating sphere. The Fourier transfer infrared spectroscopy (FTIR) was performed using Bruker Platinum ATR VERTEX 70.

\subsection{Photodegradation experiments}

The photocatalytic degradation experiments were performed in a self-made continuous stirred photochemical reactor as shown in Fig. S1 (Supplementary information). The photocatalytic reaction chamber consists of a UV lamp (rated power is $14 \mathrm{~W}$, rated voltage is $216-253 \mathrm{~V}$ at $50 \mathrm{~Hz}, \lambda_{\max }$ of $254 \mathrm{~nm}$, Trojan, Canada) placed in a quartz socket tube with one end closed, magnetic stirrer, rotor, and a reaction vessel with double- 
jacketed cooling system. The model solution (300 mL) was added inside the photochemical reactor and the temperature inside the jacketed reactor was maintained at $21 \pm 2{ }^{\circ} \mathrm{C}$ by continuous circulation of water. Prior to irradiation, measured quantity of photocatalyst was dispersed into the solution and magnetically stirred in dark for 30 min to achieve adsorption-desorption equilibrium. Upon the irradiation, an aliquot of 3 $\mathrm{mL}$ reaction solution was sampled at given time intervals. The reaction solution aliquots were then filtered through $0.45 ? \mathrm{~m}$ membranes prior to analysis. No buffer was used and the pH values ranged from 5 to 7 (before and after) during all set of the experiments.

\subsection{Trap experiments}

The radicals and holes trapping experiments were designed to elucidate the types and roles of reactive species, and mechanisms involved during the photocatalytic degradation of $\mathrm{CBZ}$ and DCF using 5\% $\mathrm{Ag}_{2} \mathrm{O} / \mathrm{P}-25$. In practice, several chemical compounds were tested during the photocatalytic processes, including ethylenediaminetetaacetic acid (EDTA) as a hole $\left(h^{+}\right)$scavenger [28], methanol $(\mathrm{MeOH})$ as hydroxyl radical $(\cdot \mathrm{OH})$ scavenger [36], and $\mathrm{O}_{2}$-purging $\left(\cdot \mathrm{O}_{2}{ }^{-}\right.$scavenger $)$via $\mathrm{N}_{2}$ [37].

\subsection{Reusability experiments}

Cyclic experiments were performed to check the reusability of the investigated photocatalyst over the degradation of CBZ and DCF. Typically, $0.24 \mathrm{~g}$ of $5 \% \mathrm{Ag}_{2} \mathrm{O} / \mathrm{P}-25$ was dispersed into $0.3 \mathrm{~L} \mathrm{CBZ}$ aqueous solution $\left(20 \mathrm{mg} \mathrm{L}^{-1}\right)$ and reaction was started as in photodegradation experiment for $180 \mathrm{~min}$. Samples were collected at the interval of $60 \mathrm{~min}, 120 \mathrm{~min}$, and $180 \mathrm{~min}$. After the first run, suspension was centrifuged at 3500 rpm for 30 min, washed thoroughly with deionized water, and again dispersed into the 
another fresh CBZ solution to start the second run. Similarly, the experiment was repeated five times.

\subsection{Analytical procedures}

The changes in the concentration of CBZ and DCF during photocatalytic reaction were analyzed using a UV-Vis spectrophotometer (Lambda 45, Perkin Elmer, USA). The absorbance was measured at $285 \mathrm{~nm}$ and $276 \mathrm{~nm}$ for CBZ and DCF, respectively, since these wavelengths correspond to the characteristic peaks of these drugs in the UV spectrum. Moreover, it should be noted that the absorbance measurements of the treated solutions might not indicate the absolute concentration of parent CBZ or DCF as some of the treated intermediate products may also absorb at similar wavelengths, thus contributing to increased absorbance. Therefore, the reported concentrations used to calculate percentage removal may account both residual parent pollutants and some of the related reaction by-products, which could underestimate to actual degradation efficiency of the parent compounds. Dissolved organic carbon (DOC) was also measured using TOC analyzer (Shimazdu, Japan) to assess the extent of mineralization.

The degradation products of CBZ were analyzed by 12-T Bruker solariXTM XR hybrid Qh-Fourier Transform Ion cyclotron resonance (FT-ICR) mass spectrometer (Bruker Daltonics, Bremen, Germany) coupled with an electrospray ionization (ESI) source (Apollo-II), operated in the positive-ion mode. The photocatalytic degradation products of CBZ (10 ? ? $\mathrm{L})$ were prepared in methanol (diluted 10:200 v/v). Acetic acid (1 v-\%) was added to the samples to aid protonation. The samples were directly infused into the ion source at a flow rate of 2 ? $\mathrm{L} \mathrm{min}^{-1}$. The ion accumulation time in the hexapole was $0.8 \mathrm{~s}$ and the time of flight from the collision cell to the ICR cell was set at $0.260 \mathrm{~ms}$. Dry nitrogen was used as drying $\left(4.0 \mathrm{~L} \mathrm{~min}^{-1}\right)$ and nebulizing gas $\left(80^{\circ} \mathrm{C}, 1.0 \mathrm{bar}\right)$. For each 
spectrum, 200 time-domain transients (4 MWord each) were co-added and full-sine apodized. The mass spectra were externally calibrated using an ES tuning mix (Agilent Technology). Bruker FTMS Control ${ }^{\mathrm{TM}} 2.1$ software was used for the instrument control and data acquisition. The mass spectra were further processed and analyzed by using Bruker DataAnalysis 4.4 software.

\section{Results and discussion}

\subsection{Screening of photocatalysts: Dark adsorption, UV-photolysis, and UV photocatalysis}

In a preliminary stage, photocatalytic degradation efficiencies of four different photocatalysts including $\mathrm{Ag}_{2} \mathrm{O} / \mathrm{P}-25, \mathrm{Sn}_{3} \mathrm{O}_{4} / \mathrm{P}-25, \mathrm{PdO} / \mathrm{P}-25$, and $\mathrm{NiO} / \mathrm{P}-25$ were tested on the selected pollutants. First, in order to evaluate the extent of adsorption and UVphotolysis of target pollutants, adsorption under dark conditions and UV-photolysis tests were carried out (Fig 1). Even though experiments were run for several hours, adsorption-desorption equilibrium was reached in $30 \mathrm{~min}$ for all the cases. At the catalyst dose of $0.4 \mathrm{~g} \mathrm{~L}^{-1}$, the percentage adsorption removal of $50 \mathrm{mg} \mathrm{L}^{-1}$ of CBZ and DCF, was around 2-9\%. Similarly, the conversion rates of CBZ and DCF during 180 min of UV-photolysis were nearly $13 \%$ and $25 \%$, respectively. The results concluded that both of the target pollutants were slightly converted under UV-photolysis. Comparable extents of $\mathrm{CBZ}$ or DCF removal by adsorption on $\mathrm{TiO}_{2}$ based photocatalysts and UV photolysis have been reported in many studies [38-40]. On the other hand, the photocatalytic degradation kinetics of as prepared catalysts were tested by irradiating the model solutions under UV lamp for $180 \mathrm{~min}$. Of the selected five photocatalyst, the highest photodegradation efficiency of $\mathrm{CBZ}$ (i.e. 55\%) was observed with $\mathrm{Ag}_{2} \mathrm{O} / \mathrm{P}-25$ 
(Fig. 1). Similarly, the degradation of DCF by $\mathrm{PdO} / \mathrm{P}-25$ and $\mathrm{Ag}_{2} \mathrm{O} / \mathrm{P}-25$ was more than $80 \%$. Based on the screening experiments, since $5 \% \operatorname{Ag}_{2} \mathrm{O} / \mathrm{P}-25$ photocatalyst accounted the highest photocatalytic activity either in case of CBZ or DCF, therefore selected for the subsequent experiments involving both target micropollutants. Moreover, the selection of $\mathrm{Ag}_{2} \mathrm{O} / \mathrm{P}-25$ over $\mathrm{PdO} / \mathrm{P}-25$ and $\mathrm{NiO} / \mathrm{P}-25$ was made because of the comparable efficiency and compatibility to both the model pollutants.

Fig 1 (Here)

\subsection{Characteristics of selected $5 \% \mathrm{Ag}_{2} \mathrm{O} / \mathrm{P}-25$ photocatalyst}

The major characteristics of as-prepared $5 \% \mathrm{Ag}_{2} \mathrm{O} / \mathrm{P}-25$ photocatalyst such as surface chemical compositions and morphology were characterized by X-ray diffraction (XRD), transmission electron microscopy (TEM), and X-ray photoelectron spectroscopy (XPS) analysis in the previous work $[34,35]$. However, we further characterized the asprepared photocatalyst by other analytical techniques such as SEM, EDX, BET, FTIR, and UV-reflectance spectra.

The morphology and elemental microanalysis of the selected $5 \% \quad \mathrm{Ag}_{2} \mathrm{O} / \mathrm{P}-25$ photocatalyst were investigated by SEM and EDX. The SEM micrographs with different magnifications are as shown in Fig. 2. The surface of P-25 nanoparticles acts as underlying substrate to absorb $\mathrm{Ag}_{2} \mathrm{O}$ nanoparticles and an average diameter of $4.4-20$ nm could evenly disperse on the surface of P-25 during pH-mediated precipitation process $[30,34]$. Presence of Ag nanoparticles on the surface of P-25 photocatalyst was confirmed by the EDX elemental analysis, which reveals the bulk compositions of Ti, 0 , 
$\mathrm{C}$, and $\mathrm{Ag}$ elements (Fig. 2i). The $\mathrm{TiO}_{2}$ nanoparticles provide numerous nucleation sites, which could be responsible for the homogeneous dispersion of $\mathrm{Ag}_{2} \mathrm{O}$ nanoparticles on the surface of $\mathrm{TiO}_{2}$ nanoparticles [30]. Furthermore, elemental mappings of $5 \% \mathrm{Ag}_{2} \mathrm{O} / \mathrm{P}-$ 25 confirms the homogenous dispersion of $\mathrm{Ag}^{+}$particles on P-25 as depicted by Fig. 2 $(d-h)$.

Fig. 2 (Here)

To further confirm the chemical composition of $5 \% \mathrm{Ag}_{2} \mathrm{O} / \mathrm{P}-25$ photocatalyst, FTIR spectroscopy was performed as depicted in Fig. S2-a. The main absorption peaks were observed at $3000,1533.67,1420,1050$ and $433.33 \mathrm{~cm}^{-1}$. The peak located at $433.33 \mathrm{~cm}^{-}$ ${ }^{1}$ could be assigned to M-O (i.e. either Ti-O or Ag-O) stretching vibration $[41,42]$. The broad absorption band at about $2976.75 \mathrm{~cm}^{-1}$ is characteristic of $\mathrm{O}-\mathrm{H}$ stretching vibration of the Ti-OH. The vibrational peaks at $1558.30,1419.43$ and $1052 \mathrm{~cm}^{-1}$ are due to stretching of $\mathrm{C}=\mathrm{O}$ group , $\mathrm{O}-\mathrm{H}$ bending and stretching of $\mathrm{C}-\mathrm{O}$ bond, respectively $[42,43]$.

The BET surface area, pore size, and pore volume of $5 \% \mathrm{Ag}_{2} \mathrm{O} / \mathrm{P}-25$ were estimated as reported in Table S2 (Supplementary information). The $\mathrm{S}_{\mathrm{BET}}$ of pure $\mathrm{TiO}_{2}(\mathrm{P}-25)$ increased slightly from $47.27 \mathrm{~m}^{2} \mathrm{~g}^{-1}$ to $54.1 \mathrm{~m}^{2} \mathrm{~g}^{-1}$ due to the deposition of $\mathrm{Ag}_{2} \mathrm{O}$ nanoparticles over P-25 surface. Likewise, the average pore size and pore volume of P25 were increased from 8.25 to $9.27 \mathrm{~nm}$ and 0.10 to $0.13 \mathrm{~cm}^{3} \mathrm{~g}^{-1}$, respectively. However, this observation indicated that the contribution of the $\mathrm{Ag}_{2} \mathrm{O}$ particles to the specific surface area of P-25 was relatively low. The increased surface area, pore size and pore 
volume showed that $\mathrm{Ag}_{2} \mathrm{O}$ particles were well dispersed over P-25 surface with limited interference with the existing pores. Similar trends in the characteristic modifications of P-25 after doping with $\mathrm{Ag}_{2} \mathrm{O}$ have been reported in other studies [44].

For the energy band gap ( $\left.E_{\mathrm{g}}\right)$ determination of semiconductors, the reflectance spectra of photocatalysts were converted to the absorbance spectra using the Kubelka-Munk functions [45] and then $E_{g}$ evaluated by using Tau plot [44-46]. The undoped P-25 showed a band gap of $3.2 \mathrm{eV}$ with the absorption peak at $\sim 395 \mathrm{~nm}$. After doping with $\mathrm{Ag}_{2} \mathrm{O}$, the wavelength threshold of the absorption peak of P-25 was between 400 and $500 \mathrm{~nm}$, with the corresponding energy band gap at $2.96 \mathrm{eV}$ as shown in Fig. S2-b (supplementary information). The decreased band gap energy inferred the chemical interactions between $\mathrm{P}-25$ and $\mathrm{Ag}_{2} \mathrm{O}$ nanoparticles. Therefore, lower energy transitions are possible in $\mathrm{Ag}_{2} \mathrm{O} / \mathrm{P}-25$ semiconductors as $\mathrm{Ag}_{2} \mathrm{O}$ could create localized energy levels in the P-25 bandgap, which evidently increases the absorption spectra in UV-vis range [44].

\subsection{Effect of catalyst dose, solution matrix, and initial substrate concentration on the removal of selected PhACs}

In order to ensure the highest absorption of photons, without generating an substantial amount of waste, determining the optimal dose of catalyst in an adopted photocatalytic system is of high importance [38,47]. In fact, several researchers have investigated the reaction kinetics as a function of catalyst dosing in photocatalytic processes [48]. In this study, the optimal dose of $5 \% \mathrm{Ag}_{2} \mathrm{O} / \mathrm{P}-25$ for the removal of $\mathrm{CBZ}$ and DCF was determined for two different solution matrices (i.e. DW and RME) as shown in Fig. 3. The catalyst dose of $0.2-1.0 \mathrm{~g} \mathrm{~L}^{-1}$ was assessed for DW matrix, whereas $0.4-1.2 \mathrm{~g} \mathrm{~L}^{-1}$ was used in the case of RME matrix. Since organic matter in RME could inhibit the 
degradation of organic pollutants, higher amount of catalyst dose is essential to achieve enhanced removal efficiencies [4]. Therefore, a higher range of catalyst dosing was selected to assess the influence of organic matter contained in the RME matrix. Table 2 shows the collective removal of target pollutants and the extent of mineralization in two solution matrices under different operating conditions.

Fig. 3 (Here)

Table 2 (Here)

The photocatalytic degradation kinetics of CBZ in DW and RME matrices are shown in Fig. 3a and 3b, respectively. In DW matrix, and after an irradiation time of $180 \mathrm{~min}$, the removal of CBZ reached from $80.4 \%$ to $89.10 \%$ while increasing the catalyst dosing from 0.2 to $0.4 \mathrm{~g} \mathrm{~L}^{-1}$. Likewise, for the case of $\mathrm{DCF}$, the removal rate increased from 87.5\% to $93.5 \%$ in DW matrix for the similar range of catalyst. The higher removal rate of DCF compared to CBZ in identical operating conditions exhibited greater affinity of DCF molecules towards photocatalytic degradation by $5 \% \mathrm{Ag}_{2} \mathrm{O} / \mathrm{P}-25$. From Fig. 3 and Table 2, it is clear that the photocatalytic degradation of both CBZ and DCF beyond the $0.4 \mathrm{~g} \mathrm{~L}^{-1}$ of catalyst dose remained constant. Therefore, $0.4 \mathrm{~g} \mathrm{~L}^{-1}$ of $5 \% \mathrm{Ag}_{2} \mathrm{O} / \mathrm{P}-25$ was concluded to be the optimum catalyst dose for the removal of both PhACs in DW matrix. Similar tendencies have been reported in earlier studies [4,47]. The limiting value $0.4 \mathrm{~g}$ $\mathrm{L}^{-1}$ might be attributed to fact that photocatalytic rate increases with catalyst dosing at the beginning and then decreases (or saturates) at higher doses due to unfavorable phenomenon, such as light scattering due to enhanced reflectance and increased opacity 
of the suspension $[48,49]$. Also, the agglomeration of solid particles due to excess dose may result in a reduction of active surface sites available for photon absorption, which eventually reduces photocatalytic efficiency [33]. Even though the number of active sites increases with more catalyst dosing, the penetration of light is to be compromised because of the shielding effect $[33,48]$. The trade-off between these two divergent phenomena results in an optimal catalyst dosing for photocatalytic processes [33]. The shielding by $\mathrm{TiO}_{2}$ particles may occur due to deactivation phenomenon of activated $\mathrm{TiO}_{2}$ molecules by collision with ground state molecules $[48,50]$. Nevertheless, the optimal catalyst dosing is highly dependent on the concentration and source/type of the pollutant and the operating conditions as well [33]. Therefore, the optimal catalyst dose of $0.4 \mathrm{~g} \mathrm{~L}^{-1}$ achieved for both CBZ and DCF in DW matrix might be different for other conditions.

On the other hand, relatively slow kinetics was observed in the experiments performed with RME matrices of both CBZ and DCF (Fig. 3b and 3d). In Table 2, an increasing trend of CBZ removal rate was clearly observed from 76.6 to $93.9 \%$ when the catalyst dose was increased from 0.4 to $0.8 \mathrm{~g} \mathrm{~L}^{-1}$. However, the removal rate decreased by nearly $3 \%$ when catalyst dose was subsequently increased beyond $0.8 \mathrm{~g} \mathrm{~L}^{-1}$. On the other hand, DCF removal rate was improved greatly when the catalyst dose was increased from 0.4 $\mathrm{g} \mathrm{L}^{-1}$ to just $0.6 \mathrm{~g} \mathrm{~L}^{-1}$, though no further remarkable enhancement was observed beyond $0.6 \mathrm{~g} \mathrm{~L}^{-1}$ of catalyst dose. Therefore, different optimal catalyst dose for CBZ (i.e. $0.8 \mathrm{~g} \mathrm{~L}^{-1}$ ) and DCF (i.e. $0.6 \mathrm{~g} \mathrm{~L}^{-1}$ ) were established in RME matrix.

As clearly seen in Table 2, there is an obvious deviation in the optimum catalyst dose of DW and RME matrices. The need for optimal catalyst dose in RME matrix, in order to achieve approximately the same level of removal efficiency in DW matrix, is increased 
by factor of 2 and 1.5 for CBZ and DCF, respectively. Therefore, the competition between organic matter and the PhACs on the surface of catalyst was evidently observed in the RME matrix during the photocatalytic process. This may be attributed to either the organic carbon content of RME samples, or the presence of various species that may act as natural scavengers and other reactive moieties [12]. The organic matter in real effluent not only competes for the active species generated in the process but could also be adsorbed on the surface of photocatalysts, which inhibits the photocatalytic activity [4]. Additionally, a possible interference of inorganic ions on catalyst surface deactivation, and a competition for UV absorption should also be taken into consideration [51].

Fig. 4 (Here)

Subsequently, the optimized catalyst doses for CBZ and DCF removal in RME matrix were used to study the influence of initial substrate concentration in photocatalytic degradation kinetics, as depicted in Fig. 4. The initial substrate concentration was varied in the range of $20-50 \mathrm{mg} \mathrm{L}^{-1}$ at optimal catalyst doses of $0.8 \mathrm{~g} \mathrm{~L}^{-1}$ and $0.6 \mathrm{~g} \mathrm{~L}^{-1}$ for CBZ and DCF, respectively. In Fig $\mathbf{4 a}$ and $\mathbf{4 b}$, decreasing trends in the removal of CBZ and DCF were observed when initial substrate concentrations were gradually increased. The removal efficiency of $\mathrm{CBZ}$ was decreased by $38 \%$, when the concentration was increased from $20-50 \mathrm{mg} \mathrm{L}^{-1}$ (Fig. 4a, inset). Whereas, only $23 \%$ reduction was observed in the DCF removal efficiency with the same range of concentration increments (Fig. 4b, inset). These trends may be attributed to the increasing occupied sites of the catalyst due to more pollutant molecules adsorbed on the surface of catalyst, 
which inhibits the generation of reactive species [12]. On the other hand, high pollutants concentrations can lead to a decreasing penetration of photons into the bulk solution and hence the solutions become more impermeable to UV irradiation due to an induced inner filtering effect. Thus, the photoexcitation of catalyst particles by photon energy will be reduced leading to a diminished photodegradation efficacy [52].

The photocatalytic oxidation of organic contaminants via heterogeneous catalytic process usually showed that the corresponding data fit the Languir-Hinselwood (L-H) kinetic model as shown in Eq. 1 [12,53]:

$\frac{\mathrm{C}_{\mathrm{eq}}}{\mathrm{r}_{0}}=\frac{\mathrm{C}_{\mathrm{eq}}}{\mathrm{k}_{\mathrm{r}}}+\frac{1}{\mathrm{Kk}_{\mathrm{r}}}$

where $r_{0}$ is the initial reaction rate, $C_{e q}$ is the equilibrium concentration of substrate in solution after the completion of dark experiments, $\mathrm{k}_{\mathrm{r}}$ is the reaction rate constant at maximum coverage, and $\mathrm{K}$ is equilibrium constant for adsorption of the substrate onto the catalyst surface.

In order to check if the investigated photocatalytic degradation follows the L-H kinetic model, the experimental data with initial concentrations of target pollutants (20 -50 mg $\mathrm{L}^{-1}$ ) in RME matrix (Fig. 5) were assessed and the initial rates were calculated at $20 \mathrm{~min}$ of initial reaction. A graphical plot of Eq. 1 for runs at various initial substrate concentrations is shown in Fig. 5, which indicates that the photocatalytic degradation well fitted the Langmuir-Hinshelwood kinetic model. Moreover, the degradation kinetics beyond 20 min of irradiation were observed to follow a curve rather than a straight line when modelled with pseudo-first order (PFO) kinetic for both CBZ and DCF compounds. The possible formation of aromatic organic intermediates, which can be 
detected at the similar wavelengths of parent compounds, could affect the corresponding final absorbance values and consequently the reaction kinetics [54].

Fig. 5 (Here)

\subsection{Mineralization of PhACs}

In order to characterize the mineralization extent of CBZ and DCF in different solution matrices, the DOC measurements were carried out during photocatalytic treatment. The optimal catalyst doses were adopted for different solution matrices and target pollutants. Fig. $6 \mathrm{a}$ and $6 \mathrm{~b}$ show the normalized DOC removals during the photocatalytic treatment of CBZ and DCF, respectively. About $68 \%$ of mineralization rate was observed when the CBZ removal was $90 \%$ in DW matrix, whereas the mineralization rate was reduced to $65 \%$ when CBZ removal was $94 \%$ in RME matrix (Table 2). Similarly, the mineralization rates of DCF for DW and RME matrices were $60 \%$ and 55\%, whilst their removals were $93 \%$ and $90 \%$, respectively. The removal percentages of both CBZ and DCF molecules by photocatalysis were noticeably higher than the corresponding removal percentage of DOC. This might be explained by the formation of aromatic organic intermediates from parent molecules of target pollutants, which leads to the increase of organic molecules in the solution $[12,40]$. Moreover, results showed that the mineralization rates of both the target compounds were inhibited to some extent in RME matrix as compared to DW matrix. This fact evidently confirms the influence of organic matter ( $c f$. Table S1) present in the RME matrix. 
Fig. 6 (Here)

\subsection{Role of reactive oxygen species and mechanism involved in the photocatalytic degradation}

The influence of reactive species $\left(h^{+}, \cdot \mathrm{OH}, \bullet^{-}\right)$involved during the photocatalytic degradation of CBZ and DCF using 5\% $\mathrm{Ag}_{2} \mathrm{O} / \mathrm{P}-25$ is shown in Fig. 7. In Fig. 7a, the photocatalytic degradation of CBZ under UV irradiation for 60 min was substantially suppressed with the addition of EDTA and $\mathrm{MeOH}$ by nearly $70 \%$ and $90 \%$, respectively, as compared to the control test. However, the degradation percentage decreased slightly (18\%) when $\mathrm{O}_{2}$-purging test was performed. The results indicated that trapped holes and hydroxyl radicals adsorbed on the surface of the $5 \% \mathrm{Ag}_{2} \mathrm{O} / \mathrm{P}-25$ were the dominant oxidative species during the photocatalytic degradation of CBZ molecules. Similarly, the degradation rate of DCF in the presence of EDTA was substantially decreased to $62 \%$ as compared to the control test (Fig. 7b). However, the effect of either $\mathrm{MeOH}$ or $\mathrm{O}_{2}$-purging was not significant $(\sim 7 \%)$, which suggests that the trapped holes were the main oxidative species prompted due to UV irradiation of $5 \% \mathrm{Ag}_{2} \mathrm{O} / \mathrm{P}$ 25 , and thus accountable for the photocatalytic degradation of DCF. Interestingly, the conversion of DCF was not influenced due to the addition of $\mathrm{MeOH}$. To confirm this result, other scavengers such as isopropyl alcohol and tert-Butanol were also tested, however similar effects were observed (data not shown). This might be due to the higher affinity of photo-generated ROS with DCF molecules, compared to the added scavengers. Moreover, the major role of photogenerated holes during the photocatalytic oxidation of $\mathrm{TiO}_{2}$ based photocatalyts has been reported [55]. In addition, the organic pollutants could also absorb actinic photons from UV irradiation and transfer energy or 
electrons to produce reactive oxidation species, which in turn degrade the organic pollutants. This phenomenon is referred to as self-sensitized photooxidation of pollutants [56].

Fig. 7 (Here)

On the basis of above results, a possible photocatalytic mechanism scheme of the heterojunction 5\% $\mathrm{Ag}_{2} \mathrm{O} / \mathrm{P}-25$ photocatalyst was proposed as shown in Fig. S3 (Supplementary information). When composite $\mathrm{Ag}_{2} \mathrm{O} / \mathrm{P}-25$ was irradiated by UV, both $\mathrm{e}^{-}$and $h^{+}$were excited in the conductance band (CB) and valence band (VB), respectively according to Eqs. 2-3. In normal case, most of $\mathrm{e}^{-}-h^{+}$pairs recombine rapidly to produce heat. As $E_{\mathrm{CB}}\left(\mathrm{TiO}_{2},-0.4 \mathrm{eV} v s\right.$. SHE) is lower than $E\left(\mathrm{O}_{2} \bullet^{\left.\cdot{ }^{\circ} 2^{-}\right)}(-0.046 \mathrm{eV}\right.$ vs. SHE), $\bullet^{-} \mathrm{O}_{2}$ could produce from dissolved $\mathrm{O}_{2}[57,58]$. However, the $E_{\mathrm{CB}}\left(\operatorname{Ag}_{2} \mathrm{O},+0.2 \mathrm{eV}\right.$ VS. SHE) was higher than $E\left(\mathrm{O}_{2} /^{\circ} \mathrm{O}^{-}\right)$, thus unable to produce ${ }^{\cdot} \mathrm{O}_{2}^{-}$from dissolved $\mathrm{O}_{2}$ $[58,59]$. The electron produced on $\mathrm{CB}$ of $\mathrm{TiO}_{2}$ can transferred easily to $\mathrm{Ag}_{2} \mathrm{O}$ as $E_{\mathrm{CB}}$ of $\mathrm{TiO}_{2}$ is positioned above that of $\mathrm{Ag}_{2} \mathrm{O}$ (Gao et al., 2017). Subsequently, the partial lattice $\mathrm{Ag}^{+}$in $\mathrm{Ag}_{2} \mathrm{O}$ nanoparticles on the surface of $\mathrm{TiO}_{2}$ reacts with photoinduced electrons and reduced to metallic Ag (Eq. 4). Further, the metallic Ag acted as an electron pool and transferred the produced electrons to combine with $\mathrm{O}_{2}$. The $\mathrm{Ag}_{2} \mathrm{O}$ as electron absorbent inhibits the recombination of the photogenerated $\mathrm{e}^{-}-h^{+}$pairs, which allows the holes to effectively oxidize organic pollutants, and thus the photocatalytic activity is highly improved [30]. Meanwhile, the generated electrons are trapped by dissolved $\mathrm{O}_{2}$ to produce ${ }^{\circ} \mathrm{O}_{2}$, and transformed to reactive oxygen species $\cdot \mathrm{OH}$ by multistep reductions (Eq. 5-8). Moreover, the $E_{\mathrm{VB}}\left(\mathrm{TiO}_{2},+2.8 \mathrm{eV} v S\right.$. SHE) was higher than the $E\left(\cdot \mathrm{OH} / \mathrm{H}_{2} \mathrm{O}\right)$ 
$\left(+2.68 \mathrm{eV}\right.$ vs. SHE) $[57,59]$, indicating that the photogenerated holes at $\mathrm{VB}$ of $\mathrm{TiO}_{2}$ could oxidize $\mathrm{H}_{2} \mathrm{O}$ to $\cdot \mathrm{OH}$ according to Eq. 9. Subsequently, photoinduced holes in the VB of $\mathrm{TiO}_{2}$ can easily move and accumulate at the $\mathrm{VB}$ of $\mathrm{Ag}_{2} \mathrm{O}$ since $E_{\mathrm{VB}}\left(\mathrm{Ag}_{2} \mathrm{O},+1.0 \mathrm{eV}\right.$ vs. SHE) is less positive than that of $\mathrm{TiO}_{2}$. As a result, the recombination potential of $\mathrm{e}^{-}-h^{+}$ pairs was largely reduced, thus greatly enhancing quantum efficiency [28]. Moreover, photoinduced holes transferred and accumulated in the VB of $\mathrm{Ag}_{2} \mathrm{O}$ could directly oxidize the target pollutants to a great extent. The photogenerated reactive species $\left(h^{+}\right.$, $\left.\cdot \mathrm{OH}, \bullet^{-}\right)$could degrade $\mathrm{CBZ}$ or $\mathrm{DCF}$ molecules into intermediates and finally to mineralization (Eq. 10).

$$
\begin{aligned}
& \mathrm{TiO}_{2} \stackrel{h \vartheta}{\rightarrow} \mathrm{e}^{-}+h^{+} \\
& \mathrm{Ag}_{2} \mathrm{O} \stackrel{h \vartheta}{\rightarrow} \mathrm{e}^{-}+h^{+} \\
& \mathrm{Ag}_{2} \mathrm{O}+\mathrm{H}_{2} \mathrm{O}+2 \mathrm{e}^{-} \rightarrow 2 \mathrm{Ag}+2 \mathrm{OH}^{-} \\
& \mathrm{e}^{-}+\mathrm{O}_{2} \rightarrow \cdot \mathrm{O}_{2}^{-} \\
& \cdot \mathrm{O}_{2}^{-}+\mathrm{H}^{+} \rightarrow \cdot \mathrm{OOH}^{-} \\
& \cdot \mathrm{OOH}^{+} \mathrm{H}^{+}+\mathrm{e}^{-} \rightarrow \mathrm{H}_{2} \mathrm{O}_{2} \\
& \mathrm{H}_{2} \mathrm{O}_{2}+\mathrm{e}^{-} \rightarrow \cdot \mathrm{OH}+\mathrm{OH}^{-} \\
& h^{+}+\mathrm{H}_{2} \mathrm{O} \rightarrow \cdot \mathrm{OH}+\mathrm{H}^{+} \\
& h^{+} \cdot \mathrm{O}_{2} \cdot \cdot \mathrm{OH}+\mathrm{CBZ} \text { or } \mathrm{DCF} \rightarrow \text { Intermediate products } \rightarrow \mathrm{CO}_{2}+\mathrm{H}_{2} \mathrm{O}
\end{aligned}
$$

\subsection{Reusability of $5 \% \mathrm{Ag}_{2} \mathrm{O} / \mathrm{P}-25$ catalyst on PhACs removal}

The reusability of any catalyst during photocatalytic process is an important factor to evaluate its performance in practical applications. For this aim, cyclic photocatalytic experiments were performed for both target pollutants on $5 \% \mathrm{Ag}_{2} \mathrm{O} / \mathrm{P}-25$, as shown in Fig. 8. After, five consecutive cycles of photocatalytic degradation of CBZ, the catalyst did not exhibit any significant loss of its activity (Fig. 8a). The results are indicative of 
the potential practical application of $\mathrm{Ag}_{2} \mathrm{O} / \mathrm{P}-25$ catalyst based on its remarkable reusability for CBZ degradation. The plausible photocatalytic activity of the selected catalyst might be attributed to the self-stability exhibited by $\operatorname{Ag}_{2} \mathrm{O}$ nanoparticles once the complex structure of $\mathrm{Ag}-\mathrm{Ag}_{2} \mathrm{O}$ is formed during the photocatalytic process [60]. Moreover, the separation of catalyst from aqueous solution was achieved in all the cycles with just 15 min of centrifugation, which leads to the conclusion that the complex catalyst synthesized can easily be recovered without high filtration costs, as normally associated with $\mathrm{TiO}_{2}$ nanoparticles [22].

On the other hand, the photocatalytic removal efficiency of DCF inhibited gradually during cyclic reuse of composite catalyst (Fig. $8 \mathrm{~b}$ ). The removal percentage of DCF dropped by $35 \%$ up to $5^{\text {th }}$ cycle as compared to $1^{\text {st }}$ cycle. Nevertheless, as the inhibition rate of the photocatalytic activity was acceptable and remained almost stable after $2^{\text {nd }}$ cycle, the synthesized 5\% $\mathrm{Ag}_{2} \mathrm{O} / \mathrm{P}-25$ demonstrated a moderately stable activity towards DCF degradation, and thus could be recommended for the long-term application. However, the inhibitory mechanism observed during the photocatalytic process of DCF under the identical working conditions of CBZ was not clear. This might be due to the possible de-activation of catalyst by surface blockage, irreversible adsorption on active sites, and aggregation of catalyst particles [47]. A clear transformation in a physical appearance of $5 \% \mathrm{Ag}_{2} \mathrm{O} / \mathrm{P}-25$ was observed before and after the reaction (Fig. S4). The interfering compounds formed during rapid initial photocatalytic process (organic by-products etc.) may block the active surface sites, allowing neither target pollutants nor reactive species to adsorb and react with photogenerated charges. Interfering compounds may act as a bridge or adhesive between the particles, and also can scavenge the generated ROS such as $\bullet \mathrm{OH}$, or $\bullet^{-} \mathrm{O}^{-}$, either discarding them or transforming into less active ones [61]. The above hypothesis might 
be partially supported by the results from trapping experiment (cf. Fig. $7 \mathrm{~b}$ ), in which the influence of $\bullet \mathrm{OH}$, and $\bullet^{-} \mathrm{O}^{-}$was negligible on the photocatalytic degradation of DCF.

Fig. 8 (Here)

\subsection{CBZ intermediates identification and possible degradation pathway}

Of the selected PhACs, transformation products formed during the photocatalytic degradation of CBZ (as an illustrative) using $\mathrm{Ag}_{2} \mathrm{O} / \mathrm{P}-25$ under UV irradiation were analyzed using high-resolution FT-ICR mass spectrometry and detected based on their accurate masses and deduced elemental formulae (Table S3, supplementary information). The common transformation products of CBZ such as 10,11- dihydro-CBZ10,11-epoxide (m/z 253), acridine-9-carboxaldehyde (m/z 208), hydroxyacridine-9carboxaldehyde (m/z 224) $[38,39,50,62]$ were detected. The photocatalysis transforms CBZ to degradation products showing other ecological properties [50]. The large number of compounds formed during the photocatalytic degradation evidences the complexity involved in the photocatalysis of $\mathrm{CBZ}$, thus indicating the possible occurrence of multi-step degradation routes and interconnected pathways [16].

A photocatalytic degradation mechanism of CBZ shown in Fig. 9 was proposed based on the degradation products unambiguously identified photoproducts in this study and proposals of the previous literatures $[38,39,62,50]$. The short-lived proposed intermediates are in the brackets, while stable intermediates are inside the parentheses. Since substituents could appear in different positions in the aromatic rings, they have been represented as crossing the parenthesis marks. As verified by the quenching 
experiments, the major reactive species involved in photocatalytic degradation of CBZ in aqueous $\mathrm{Ag}_{2} \mathrm{O} / \mathrm{P}-25$ suspensions were photogenerated $h^{+}$and $\bullet \mathrm{OH}$ radicals.

Fig. 9 (Here)

In photocatalytic process, hydroxylation of aromatic rings by $\bullet \mathrm{OH}$ radicals promotes the sequential ring cleavage reactions [7]. There might be two different routes (a, and $\mathbf{b}$ ) when photogenerated $\cdot \mathrm{OH}$ radicals react with $\mathrm{CBZ}$ to form hydroxy-CBZ. First, $\cdot \mathrm{OH}$ radical attacks the aromatic ring of $\mathrm{CBZ}$, which forms intermediate 1 via route $\mathbf{b}$. The intermediate 1 can further be transformed into intermediate 6 (oxcarbamazepine). Alternatively, intermediate 2 (epoxide-CBZ) and intermediate 5 ((2carboxyphenyl)amino-5-hydroxybenzoic acid) form via route a due to short-lived reaction intermediate, hydroxy-CBZ. The reaction of intermediate 2 with $\cdot \mathrm{OH}$ radicals can form other degradation products, such as intermediate 3 (acridine-9carboxaldeyde). The ring cleavage in the intermediate 3 is followed by the loss of amide group, which leads to an undetected intermediate, which further reacts with $\cdot \mathrm{OH}$ to form intermediate 4 (hydroxyacridine-9-carboxaldehyde). Due to ring cleavage, intermediate 5 can further be transformed into other intermediates 6 (anthranilic/salicylic acid) and 7 (cathecol). Finally, the complex hydroxylated intermediates and low molecular mass compounds can be oxidized through ringrupturing reactions to aliphatic compounds and further oxidation to mineralization ( $\mathrm{CO}_{2}$ and $\mathrm{H}_{2} \mathrm{O}$ ). 


\section{Conclusion}

A heterojunction 5\% $\mathrm{Ag}_{2} \mathrm{O} / \mathrm{P}-25$ was selected as an efficient photocatalyst by a screening assessment of four different photocatalysts. Dark adsorption, UV photolysis and photocatalytic kinetics of target pollutants were investigated as preliminary tests. The selected 5\% $\mathrm{Ag}_{2} \mathrm{O} / \mathrm{P}-25$ catalyst was prepared and characterized by SEM, EDX, BET, and UV-vis diffuse reflectance spectra. The effects of catalyst dose, initial pollutants concentration, and mineralization during the photocatalytic degradation of CBZ and DCF were investigated in both DW and RME solution matrices. The optimal CBZ and DCF removals of $89.10 \%$ and $93.5 \%$, respectively for 180 min of UV irradiation were observed at catalyst dose of $0.4 \mathrm{~g} \mathrm{~L}^{-1}$ in DW matrix. However, the optimal catalyst doses for CBZ and DCF in RME matrix were respectively increased by factor 2 and 1.5, to achieve the same level of removal, which may be due the influence of organic matters and natural scavengers in the real effluents. A noticeable decreasing trends in removal rates were observed with the increased initial concentration of both $\mathrm{PhAC}$, and kinetics seem to fit the Langmuir-Hinshelwood model. A substantial improvement in mineralization was also achieved. The results showed that photoinduced holes and $\bullet \mathrm{OH}$ were the dominant oxidation species in the photocatalytic degradation of PhACs. A possible reaction mechanism and energy band matching of complex 5\% $\mathrm{Ag}_{2} \mathrm{O} / \mathrm{P}-25$ was also demonstrated. Good reusability was exhibited by the selected photocatalyst during photocatalytic degradation of target PhACs, ensuring its aptitude for practical 
applications. Moreover, multiple routes of the CBZ transformation and various

intermediates formed during photocatalytic degradation were studied and a possible multi-step degradation path was proposed.

\section{Acknowledgement}

This work was financially supported by Business Finland Oy (Innovaatiorahoituskeskus) (formerly Tekes- the Finnish Funding Agency for Technology and Innovation) - A research funding for the Smart Effluents Project. Authors heartily thank Reijo Turkki (Director of Mikkeli Vesilaitos), Risto Repo, Anne Bergman, and Päivi Luukkonen for their consistent support to this work. The FT-ICR MS facility is supported by Biocenter Finland/Biocenter Kuopio and European Regional Development Fund (Grant A70135).

\section{References}

[1] Y. Zhang, S.-U. Geißen, C. Gal, Carbamazepine and diclofenac: Removal in wastewater treatment plants and occurrence in water bodies, Chemosphere. 73 (2008) 1151-1161. doi:10.1016/j.chemosphere.2008.07.086.

[2] Y. Lu, P. Hernandez, D. Abegunde, T. Edejer, The World Medicines Situation 2011 Medicine Expenditures, World Health Organ. 3 (2011) 1-34.

[3] O. Gimeno, J.F. García-Araya, F.J. Beltrán, F.J. Rivas, A. Espejo, Removal of emerging contaminants from a primary effluent of municipal wastewater by means of sequential biological degradation-solar photocatalytic oxidation processes, Chem. Eng. J. 290 (2016) 12-20. doi:10.1016/j.cej.2016.01.022.

[4] R.P. Cavalcante, R.F. Dantas, H. Wender, B. Bayarri, O. González, J. Giménez, S. Esplugas, A. Machulek, Photocatalytic treatment of metoprolol with B-doped TiO2: Effect of water matrix, toxicological evaluation and identification of intermediates, Appl. Catal. B Environ. 176-177 (2015) 173-182. doi:10.1016/j.apcatb.2015.04.007.

[5] J. Zhang, B. Sun, X. Xiong, N. Gao, W. Song, E. Du, X. Guan, G. Zhou, Removal of emerging pollutants by Ru/TiO2-catalyzed permanganate oxidation, Water Res. 63 (2014) 262-270. doi:10.1016/j.watres.2014.06.028. 
[6] N. Vieno, M. Sillanpää, Fate of diclofenac in municipal wastewater treatment plant - A review, Environ. Int. 69 (2014) 28-39. doi:10.1016/j.envint.2014.03.021.

[7] J. Xu, L. Li, C. Guo, Y. Zhang, W. Meng, Photocatalytic degradation of carbamazepine by tailored BiP04: efficiency, intermediates and pathway, Appl. Catal. B Environ. 130-131 (2013) 285-292. doi:10.1016/j.apcatb.2012.11.013.

[8] M. Clara, B. Strenn, O. Gans, E. Martinez, N. Kreuzinger, H. Kroiss, Removal of selected pharmaceuticals, fragrances and endocrine disrupting compounds in a membrane bioreactor and conventional wastewater treatment plants, Water Res. 39 (2005) 47974807. doi:10.1016/j.watres.2005.09.015.

[9] EU, EU. Directive 2013/39/EU of the European Parliament and of the Council, 2013 (2013) 1-17.

[10] K. Gurung, M.C. Ncibi, M. Shestakova, M. Sillanpää, Removal of carbamazepine from MBR effluent by electrochemical oxidation (EO) using a Ti/Ta205-SnO2 electrode, Appl. Catal. B Environ. 221 (2018) 329-338. doi:10.1016/j.apcatb.2017.09.017.

[11] L. Haroune, M. Salaun, A. Ménard, C.Y. Legault, J.-P. Bellenger, Photocatalytic degradation of carbamazepine and three derivatives using $\mathrm{TiO} 2$ and $\mathrm{ZnO}$ : Effect of $\mathrm{pH}$, ionic strength, and natural organic matter, Sci. Total Environ. 475 (2014) 16-22. doi:10.1016/j.scitotenv.2013.12.104.

[12] E. Hapeshi, A. Achilleos, M.I. Vasquez, C. Michael, N.P. Xekoukoulotakis, D. Mantzavinos, D. Kassinos, Drugs degrading photocatalytically: Kinetics and mechanisms of ofloxacin and atenolol removal on titania suspensions, Water Res. 44 (2010) 1737-1746. doi:10.1016/j.watres.2009.11.044.

[13] N. Vieno, T. Tuhkanen, L. Kronberg, Elimination of pharmaceuticals in sewage treatment plants in Finland, Water Res. 41 (2007) 1001-1012. doi:10.1016/j.watres.2006.12.017.

[14] S. Judd, The status of membrane bioreactor technology, Trends Biotechnol. 26 (2008) 109-116. doi:10.1016/j.tibtech.2007.11.005.

[15] K. Gurung, M.C. Ncibi, M. Sillanpää, Assessing membrane fouling and the performance of pilot-scale membrane bioreactor (MBR) to treat real municipal wastewater during winter season in Nordic regions, Sci. Total Environ. 579 (2017) 1289-1297. doi:10.1016/j.scitotenv.2016.11.122.

[16] T.E. Doll, F.H. Frimmel, Kinetic study of photocatalytic degradation of carbamazepine, clofibric acid, iomeprol and iopromide assisted by different TiO2 materialsdetermination of intermediates and reaction pathways, Water Res. 38 (2004) 955-964. doi:10.1016/j.watres.2003.11.009.

[17] S.B. Hammouda, F. Zhao, Z. Safaei, I. Babu, D.L. Ramasamy, M. Sillanpää, Reactivity of novel Ceria-Perovskite composites $\mathrm{CeO} 2-\mathrm{LaMO} 3(\mathrm{MCu}, \mathrm{Fe})$ in the catalytic wet peroxidative oxidation of the new emergent pollutant 'Bisphenol F': Characterization, kinetic and mechanism studies, Appl. Catal. B Environ. 218 (2017) 119-136. doi:10.1016/j.apcatb.2017.06.047.

[18] F. Méndez-Arriaga, S. Esplugas, J. Giménez, Degradation of the emerging contaminant ibuprofen in water by photo-Fenton, Water Res. 44 (2010) 589-595. doi:10.1016/j.watres.2009.07.009.

[19] M.M. Huber, S. Canonica, G.-Y. Park, U. von Gunten, Oxidation of Pharmaceuticals during Ozonation and Advanced Oxidation Processes, Environ. Sci. Technol. 37 (2003) 10161024. doi:10.1021/es025896h.

[20] L. Hu, H.M. Martin, O. Arce-Bulted, M.N. Sugihara, K.A. Keating, T.J. Strathmann, Oxidation of Carbamazepine by $\mathrm{Mn}(\mathrm{VII})$ and $\mathrm{Fe}(\mathrm{VI})$ : Reaction Kinetics and Mechanism, Environ. Sci. Technol. 43 (2009) 509-515. doi:10.1021/es8023513.

[21] D. Chen, Z. Huang, H. Quan, S. Chen, J. Lin, X. Luo, L. Guo, Mesoporous Single Crystal Rutile TiO2 Rods Modified with Ag Nanoparticles as a Photocatalyst for Degradation of Pollutants, Sci. Adv. Mater. 8 (2016) 1005-1009. doi:10.1166/sam.2016.2668.

[22] H. Dong, G. Zeng, L. Tang, C. Fan, C. Zhang, X. He, Y. He, An overview on limitations of TiO2based particles for photocatalytic degradation of organic pollutants and the corresponding countermeasures, Water Res. 79 (2015) 128-146. doi:10.1016/j.watres.2015.04.038. 
[23] J.C. Joo, G.Y. Kim, C.H. Ahn, S. Lee, J.-R. Park, J.K. Kim, Development of Titanium Dioxide (Ti02)-Embedded Buoyant Photocatalyst Balls Using Expanded Polystyrene, J. Nanosci. Nanotechnol. 19 (2019) 1065-1068. doi:10.1166/jnn.2019.15935.

[24] Z. Li, F. Huang, H. Mo, A. Yan, H. Zhao, R. Xu, H. Dong, Q. Gao, Two-Step Solvothermal Method Assisted by Ultrasonic Exfoliation to Construct Nb307F/MoSe2 Hybrids with Enhanced Photocatalytic Activity, Sci. Adv. Mater. 9 (2018) 1626-1630. doi:10.1166/sam.2017.3182.

[25] P. Xiao, J.-H. Kim, S. Seo, Simple Fabrication of Highly Sensitive Photodetectors Using MoS2 Nanoparticles and Ag Nanowires, Sci. Adv. Mater. 9 (2017) 1626-1630. doi:10.1166/sam.2017.3182.

[26] Q. Tong, T. Jiao, H. Guo, J. Zhou, Y. Wu, Q. Zhang, Q. Peng, Facile Synthesis of Highly Crystalline $\alpha$-Fe2O3 Nanostructures with Different Shapes as Photocatalysts for Waste Dye Treatment, Sci. Adv. Mater. 8 (2016) 180-184. doi:10.1166/sam.2016.2625.

[27] D. Wang, G. Xue, Y. Zhen, F. Fu, D. Li, Monodispersed Ag nanoparticles loaded on the surface of spherical Bi 2 WO 6 nanoarchitectures with enhanced photocatalytic activities, J. Mater. Chem. 22 (2012) 4751-4758. doi:10.1039/C2JM14448D.

[28] X. Hu, Q. Zhu, X. Wang, N. Kawazoe, Y. Yang, Nonmetal-metal-semiconductor-promoted $\mathrm{P} / \mathrm{Ag} / \mathrm{Ag} 2 \mathrm{0} / \mathrm{Ag} 3 \mathrm{PO} 4$ /TiO 2 photocatalyst with superior photocatalytic activity and stability, J. Mater. Chem. A. 3 (2015) 17858-17865. doi:10.1039/C5TA05153C.

[29] Z. Jiang, S. Le, Y. Xie, Q. Huang, B. Wang, T. Jiang, mpg-C3N4/Ag2O Nanocomposites Photocatalysts with Enhanced Visible-Light Photocatalytic Performance, J. Nanosci. Nanotechnol. 19 (2019) 721-728. doi:10.1166/jnn.2019.15732.

[30] W. Zhou, H. Liu, J. Wang, D. Liu, G. Du, J. Cui, Ag20/TiO2 Nanobelts Heterostructure with Enhanced Ultraviolet and Visible Photocatalytic Activity, ACS Appl. Mater. Interfaces. 2 (2010) 2385-2392. doi:10.1021/am100394x.

[31] J. Han, H. Jeong, H.-D. Kim, H. Song, K. Choi, J. Park, Erbium-Doped TiO2 Hollow Sphere as a Visible-Light-Sensitive Photocatalyst, Nanosci. Nanotechnol. Lett. 10 (2018) 1152-1156. doi:10.1166/nnl.2018.2747.

[32] Y. Xu, M.A.A. Schoonen, The absolute energy positions of conduction and valence bands of selected semiconducting minerals, Am. Mineral. 85 (2000) 543-556. doi:10.2138/am2000-0416.

[33] S. Ahmed, M.G. Rasul, W.N. Martens, R. Brown, M.A. Hashib, Advances in Heterogeneous Photocatalytic Degradation of Phenols and Dyes in Wastewater: A Review, Water. Air. Soil Pollut. 215 (2011) 3-29. doi:10.1007/s11270-010-0456-3.

[34] H.-T. Ren, S.-Y. Jia, J.-J. Zou, S.-H. Wu, X. Han, A facile preparation of Ag20/P25 photocatalyst for selective reduction of nitrate, Appl. Catal. B Environ. 176-177 (2015) 53-61. doi:10.1016/j.apcatb.2015.03.038.

[35] H.-T. Ren, Q. Yang, Fabrication of Ag20/TiO2 with enhanced photocatalytic performances for dye pollutants degradation by a pH-induced method, Appl. Surf. Sci. 396 (2017) 530538. doi:10.1016/j.apsusc.2016.10.191.

[36] Y. Du, J. Rabani, The Measure of TiO2 Photocatalytic Efficiency and the Comparison of Different Photocatalytic Titania, J. Phys. Chem. B. 107 (2003) 11970-11978. doi:10.1021/jp035491z.

[37] C. Pan, Y. Zhu, New Type of BiP04 Oxy-Acid Salt Photocatalyst with High Photocatalytic Activity on Degradation of Dye, Environ. Sci. Technol. 44 (2010) 5570-5574. doi:10.1021/es101223n.

[38] C. Martínez, M. Canle L., M.I. Fernández, J.A. Santaballa, J. Faria, Kinetics and mechanism of aqueous degradation of carbamazepine by heterogeneous photocatalysis using nanocrystalline $\mathrm{TiO} 2, \mathrm{ZnO}$ and multi-walled carbon nanotubes-anatase composites, Appl. Catal. B Environ. 102 (2011) 563-571. doi:10.1016/j.apcatb.2010.12.039.

[39] M. Nawaz, W. Miran, J. Jang, D.S. Lee, One-step hydrothermal synthesis of porous 3D reduced graphene oxide/TiO2 aerogel for carbamazepine photodegradation in aqueous solution, Appl. Catal. B Environ. 203 (2017) 85-95. doi:10.1016/j.apcatb.2016.10.007. 
[40] L. Rizzo, S. Meric, D. Kassinos, M. Guida, F. Russo, V. Belgiorno, Degradation of diclofenac by TiO2 photocatalysis: UV absorbance kinetics and process evaluation through a set of toxicity bioassays, Water Res. 43 (2009) 979-988. doi:10.1016/j.watres.2008.11.040.

[41] Ö. Kerkez, İ. Boz, Photodegradation of Methylene Blue with Ag20/TiO2 under Visible Light: Operational Parameters, Chem. Eng. Commun. 202 (2015) 534-541. doi:10.1080/00986445.2013.853292.

[42] R. Lamba, A. Umar, S.K. Mehta, S.K. Kansal, Enhanced visible light driven photocatalytic application of Ag2O decorated ZnO nanorods heterostructures, Sep. Purif. Technol. 183 (2017) 341-349. doi:10.1016/j.seppur.2017.03.070.

[43] R. Lamba, A. Umar, S.K. Mehta, S.K. Kansal, CeO2ZnO hexagonal nanodisks: Efficient material for the degradation of direct blue 15 dye and its simulated dye bath effluent under solar light, J. Alloys Compd. 620 (2015) 67-73. doi:10.1016/j.jallcom.2014.09.101.

[44] S.A. Khan, S. Ali, M. Sohail, M.A. Morsy, Z.H. Yamani, Fabrication of TiO2/Ag/Ag20 Nanoparticles to Enhance the Photocatalytic Activity of Degussa P25 Titania, Aust. J. Chem. 69 (2016) 41-46. doi:10.1071/CH15250.

[45] Y.C. Zhang, Z.N. Du, K.W. Li, M. Zhang, D.D. Dionysiou, High-Performance Visible-LightDriven SnS2/SnO2 Nanocomposite Photocatalyst Prepared via In situ Hydrothermal Oxidation of SnS2 Nanoparticles, ACS Appl. Mater. Interfaces. 3 (2011) 1528-1537. doi:10.1021/am200102y.

[46] D. Wodka, R.P. Socha, E. Bielańska, M. Elżbieciak-Wodka, P. Nowak, P. Warszyński, Photocatalytic activity of titanium dioxide modified by Fe203 nanoparticles, Appl. Surf. Sci. 319 (2014) 173-180. doi:10.1016/j.apsusc.2014.08.010.

[47] G. Laera, B. Jin, H. Zhu, A. Lopez, Photocatalytic activity of TiO2 nanofibers in simulated and real municipal effluents, Catal. Today. 161 (2011) 147-152. doi:10.1016/j.cattod.2010.10.037.

[48] M.Y. Ghaly, T.S. Jamil, I.E. El-Seesy, E.R. Souaya, R.A. Nasr, Treatment of highly polluted paper mill wastewater by solar photocatalytic oxidation with synthesized nano TiO2, Chem. Eng. J. 168 (2011) 446-454. doi:10.1016/j.cej.2011.01.028.

[49] M.S.T. Gonçalves, A.M.F. Oliveira-Campos, E.M.M.S. Pinto, P.M.S. Plasência, M.J.R.P. Queiroz, Photochemical treatment of solutions of azo dyes containing TiO2, Chemosphere. 39 (1999) 781-786. doi:10.1016/S0045-6535(99)00013-2.

[50] T.E. Doll, F.H. Frimmel, Removal of selected persistent organic pollutants by heterogeneous photocatalysis in water, Catal. Today. 101 (2005) 195-202. doi:10.1016/j.cattod.2005.03.005.

[51] N. De la Cruz, R.F. Dantas, J. Giménez, S. Esplugas, Photolysis and TiO2 photocatalysis of the pharmaceutical propranolol: Solar and artificial light, Appl. Catal. B Environ. 130-131 (2013) 249-256. doi:10.1016/j.apcatb.2012.10.003.

[52] J. Deng, Y. Shao, N. Gao, S. Xia, C. Tan, S. Zhou, X. Hu, Degradation of the antiepileptic drug carbamazepine upon different UV-based advanced oxidation processes in water, Chem. Eng. J. 222 (2013) 150-158. doi:10.1016/j.cej.2013.02.045.

[53] K.V. Kumar, K. Porkodi, F. Rocha, Langmuir-Hinshelwood kinetics - A theoretical study, Catal. Commun. 9 (2008) 82-84. doi:10.1016/j.catcom.2007.05.019.

[54] L. Rizzo, S. Meric, M. Guida, D. Kassinos, V. Belgiorno, Heterogenous photocatalytic degradation kinetics and detoxification of an urban wastewater treatment plant effluent contaminated with pharmaceuticals, Water Res. 43 (2009) 4070-4078. doi:10.1016/j.watres.2009.06.046.

[55] Y. Tamaki, A. Furube, M. Murai, K. Hara, R. Katoh, M. Tachiya, Direct Observation of Reactive Trapped Holes in TiO2 Undergoing Photocatalytic Oxidation of Adsorbed Alcohols: Evaluation of the Reaction Rates and Yields, J. Am. Chem. Soc. 128 (2006) 416417. doi:10.1021/ja055866p.

[56] N. Zhang, G. Liu, H. Liu, Y. Wang, Z. He, G. Wang, Diclofenac photodegradation under simulated sunlight: Effect of different forms of nitrogen and Kinetics, J. Hazard. Mater. 192 (2011) 411-418. doi:10.1016/j.jhazmat.2011.05.038. 
[57] J. Gao, C. Liu, F. Wang, L. Jia, K. Duan, T. Liu, Facile Synthesis of Heterostructured WS2/Bi2MoO6 as High-Performance Visible-Light-Driven Photocatalysts, Nanoscale Res. Lett. 12 (2017) 377. doi:10.1186/s11671-017-2157-y.

[58] X. Wang, S. Li, H. Yu, J. Yu, S. Liu, Ag2O as a New Visible-Light Photocatalyst: Self-Stability and High Photocatalytic Activity, Chem. - Eur. J. 17 (2011) 7777-7780. doi:10.1002/chem.201101032.

[59] L. Shi, L. Liang, J. Ma, F. Wang, J. Sun, Enhanced photocatalytic activity over the Ag 2 O-g-C 3 N 4 composite under visible light, Catal. Sci. Technol. 4 (2014) 758-765. doi:10.1039/C3CY00871A.

[60] H. Yu, R. Liu, X. Wang, P. Wang, J. Yu, Enhanced visible-light photocatalytic activity of Bi2W06 nanoparticles by Ag20 cocatalyst, Appl. Catal. B Environ. 111-112 (2012) 326333. doi:10.1016/j.apcatb.2011.10.015.

[61] A. Katz, A. McDonagh, L. Tijing, H.K. Shon, Fouling and Inactivation of Titanium DioxideBased Photocatalytic Systems, Crit. Rev. Environ. Sci. Technol. 45 (2015) 1880-1915. doi:10.1080/10643389.2014.1000763.

[62] D. Vogna, R. Marotta, R. Andreozzi, A. Napolitano, M. d'Ischia, Kinetic and chemical assessment of the UV/H2O2 treatment of antiepileptic drug carbamazepine, Chemosphere. 54 (2004) 497-505. doi:10.1016/S0045-6535(03)00757-4. 


\section{Figure Captions:}

Fig. 1. Dark adsorption, UV-photolysis, and photocatalytic degradation trends of different photocatalyts for (a) CBZ, and (b) DCF. (Operating conditions: $[\mathrm{CBZ}]_{0}=[\mathrm{DCF}]_{0}=50 \mathrm{mg} \mathrm{L}^{-1},[(5 \%$ $\left.\left.\mathrm{w} / \mathrm{w}) \mathrm{Ag}_{2} \mathrm{O} / \mathrm{P}-25\right]=0.4 \mathrm{~g} \mathrm{~L}^{-1}\right)$.

Fig. 2. SEM micrographs of different magnifications (a -c); Elemental mappings (d-h): (d) total mapping, (e-h) C, O, Ti, and Ag mappings; and (i) EDX microanalysis of (5\% w/w) $\mathrm{Ag}_{2} \mathrm{O} / \mathrm{P}-25$ selected and as-prepared photocatalyst.

Fig. 3. Effect of catalyst dosing and water matrix on the photocatalytic degradation of (a) CBZ in DW, (b) CBZ in RME; and (c) DCF in DW, and (d) DCF in RME. (Operating conditions: $[\mathrm{CBZ}]_{0}=[\mathrm{DCF}]_{0}=20 \mathrm{mg} \mathrm{L}^{-1} ; \mathrm{pH}=5-7 ;\left[5 \% \mathrm{Ag}_{2} \mathrm{O} / \mathrm{P}-25\right]=0.2-1.0 \mathrm{~g} \mathrm{~L}^{-1}$ for DW matrix and $0.4-$ $1.2 \mathrm{~g} \mathrm{~L}^{-1}$ for RME matrix; Temperature $=21 \pm 2{ }^{\circ} \mathrm{C}$ ).

Fig 4. Effect of initial substrate concentration in photocatalytic degradation of (a) CBZ, and (b) DCF. (Operating conditions: All are RME matrix; [5\% $\left.\mathrm{Ag}_{2} \mathrm{O} / \mathrm{P}-25\right]=0.8 \mathrm{~g} \mathrm{~L}^{-1}$ for CBZ; and $0.6 \mathrm{~g} \mathrm{~L}^{-}$ 1 for DCF). Removal percentages of CBZ and DCF versus initial concentrations are shown in insets of (a), and (b), respectively.

Fig. 5. Fitting of L-H model for photocatalytic degradation kinetics of CBZ and DCF. (Operating conditions: RME solution matrix, $\left.\left[5 \% \mathrm{Ag}_{2} \mathrm{O} / \mathrm{P}-25\right)\right]_{0}=0.8 \mathrm{~g} \mathrm{~L}^{-1}$ for CBZ, and $0.6 \mathrm{~g} \mathrm{~L}^{-1}$ for DCF). Plot of Eq.1.

Fig. 6. Mineralization during photocatalytic degradation of (a) CBZ , and (b) DCF in two solution matrices. (Operating conditions: $\left[5 \% \mathrm{Ag}_{2} \mathrm{O} / \mathrm{P}-25\right]=0.4 \mathrm{~g} \mathrm{~L}^{-1}$ in DW matrix for both $\mathrm{CBZ}$ and DCF; and $0.8 \mathrm{~g} \mathrm{~L}^{-1}$ and $0.6 \mathrm{~g} \mathrm{~L}^{-1}$ in RME matrix for CBZ and DCF, respectively).

Fig. 7. Trap experiments to assess the role of reactive species during the photocatalytic degradation of (a) CBZ, and (b) DCF. (Operating conditions: $[\mathrm{CBZ}]_{0}=[\mathrm{DCF}]_{0}=20 \mathrm{mg} \mathrm{L}^{-1}$; $[5 \%$ $\left.\left.\mathrm{Ag}_{2} \mathrm{O} / \mathrm{P}-25\right]=0.4 \mathrm{~g} \mathrm{~L}^{-1}\right)$ 
Fig. 8. Cyclic experiments in the photocatalytic degradation of (a) CBZ, and (b) DCF over 5\% $\mathrm{Ag}_{2} \mathrm{O} / \mathrm{P}-25$.

Fig. 9. Proposed photodegradation pathway of $\mathrm{CBZ}$ by $\mathrm{Ag}_{2} \mathrm{O} / \mathrm{P}-25$ under UV light irradiation. $[\mathrm{CBZ}]_{0}=20 \mathrm{mg} \mathrm{L}^{-1}$, Catalyst dosage $=0.4 \mathrm{~g} \mathrm{~L}^{-1}$.

\section{Table Legends:}

Table 1. The physico-chemical properties of target PhACs in this study.

Table 2. Removal rates of CBZ and DCF under the varying catalyst dosing and extent of mineralization in two different water matrices. 


\section{Supplementary files}

Fig. S1 Experimental set-up for photocatalytic reactions

Fig. S2 FTIR spectrum (a) and plots of $(F(R \infty) h v)^{1 / 2} v s(h v)$ for the approximation of the optical band gap (b) of $5 \% \mathrm{Ag}_{2} \mathrm{O} / \mathrm{P}-25$

Fig. S3 Possible photocatalytic mechanism and energy band matching of 5\% $\mathrm{Ag}_{2} \mathrm{O} / \mathrm{P}-25$ under UV irradiation

Fig. S4 Change in physical appearance of $5 \% \mathrm{Ag}_{2} \mathrm{O} / \mathrm{P}-25$ during photocatalytic reaction with CBZ and DCF

Table S1 Characteristics of MBR effluent

Table S2 BET surface area $\left(\mathrm{S}_{\mathrm{BET}}\right)$, pore size, and pore volume of photocatalysts

Table S3. The putative and identified degradation products of CBZ based on ESI FT-ICR mass data 


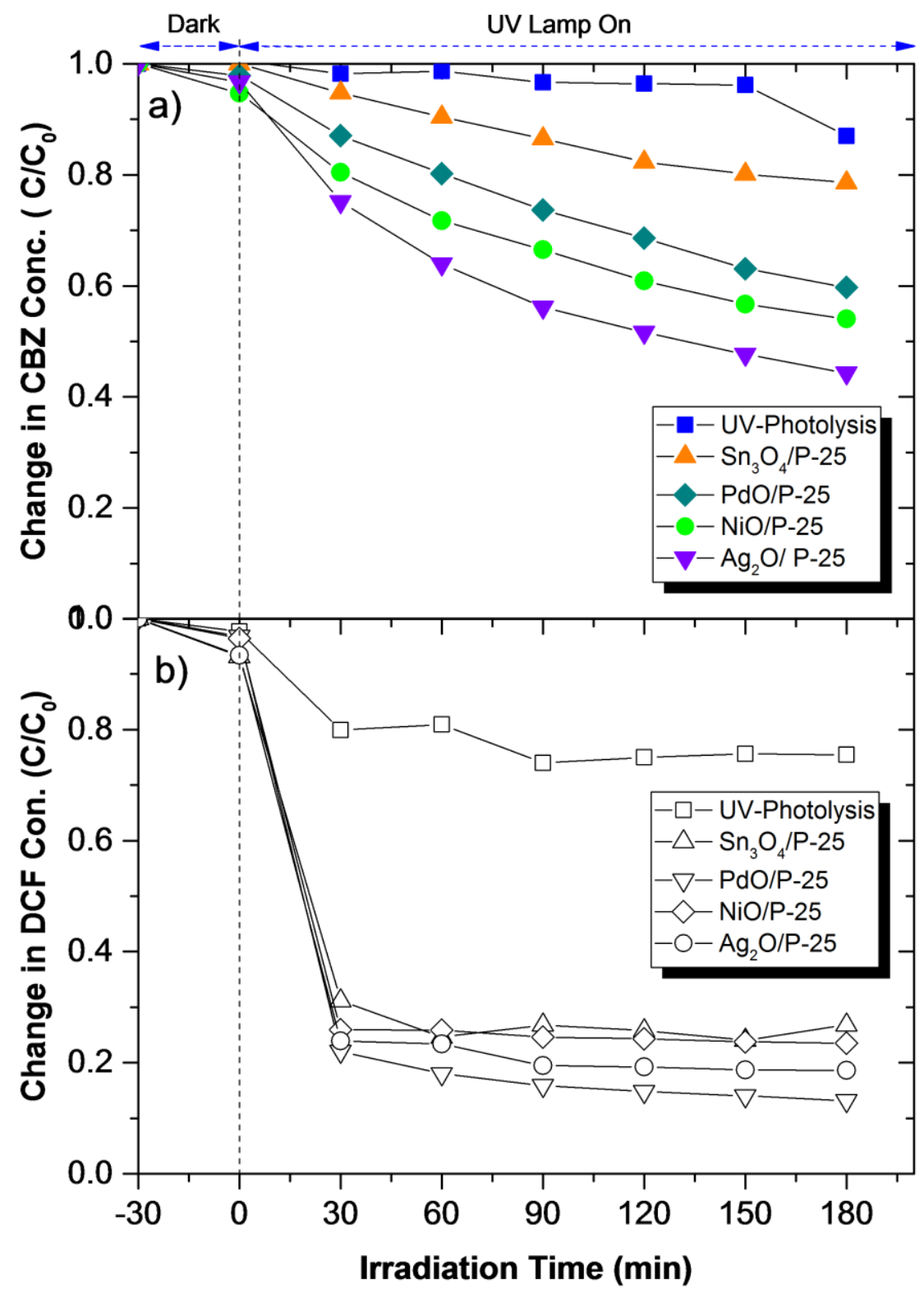

Fig. 1. Dark adsorption, UV-photolysis, and photocatalytic degradation trends of different heterogeneous photocatalyts for (a) CBZ, and (b) DCF. (Operating conditions: $\lceil\mathrm{CBZ}]_{0}=[\mathrm{DCF}\rceil_{0}=50 \mathrm{mg} \mathrm{L}^{-1}$, Catalyst dosage $\left.=0.4 \mathrm{~g} \mathrm{~L}^{-1}\right)$ 

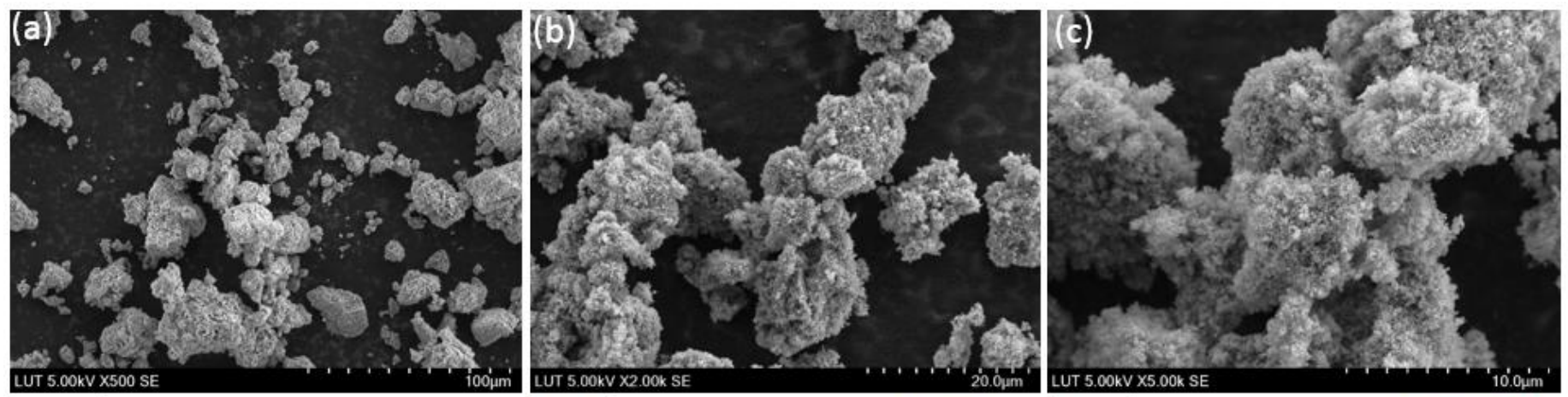

\section{Grey}

$242 \mathrm{C} \mathrm{K}$

15 OK

$0 \longdiv { 1 9 }$
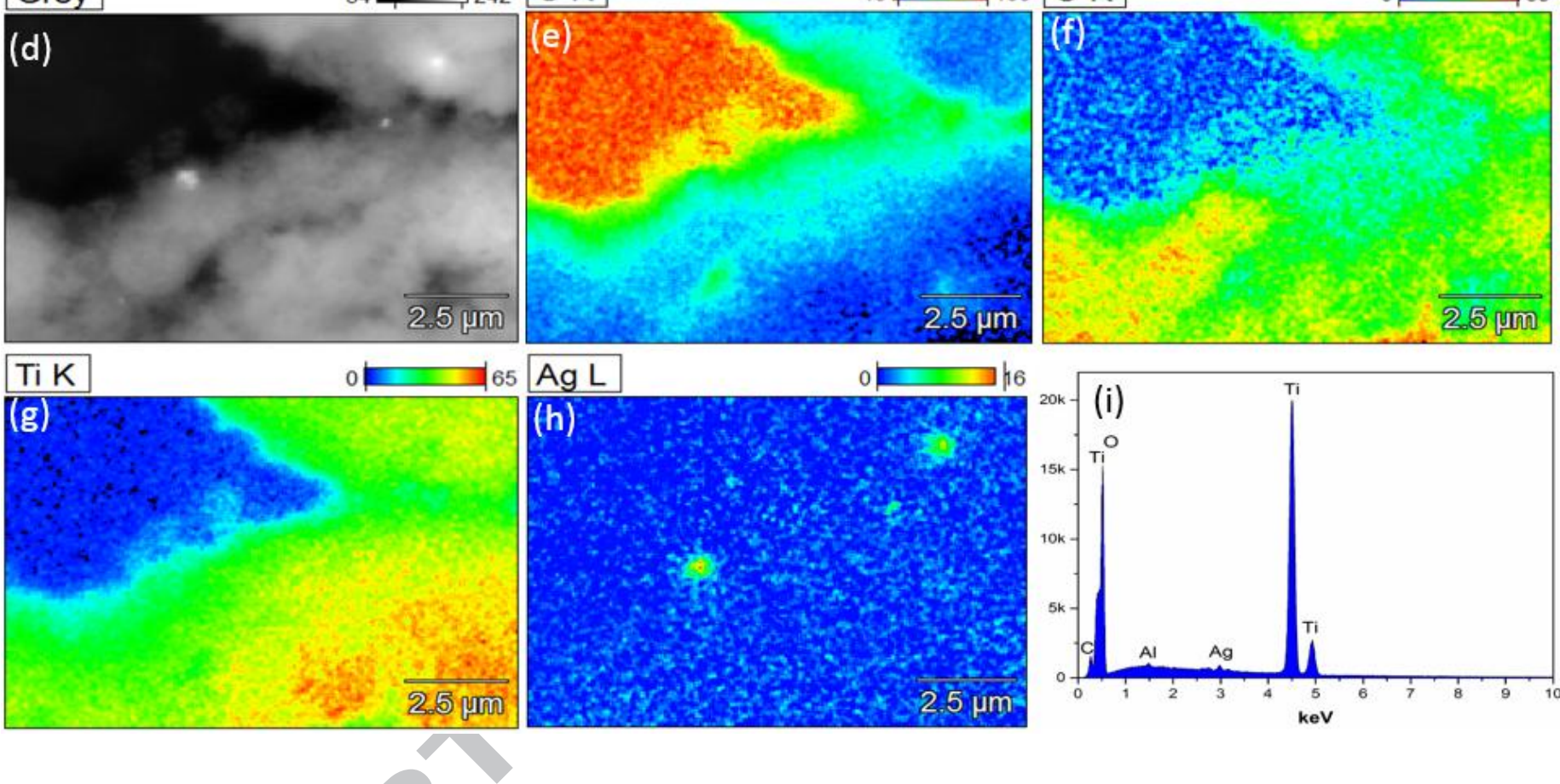

$\mathrm{Ag} \mathrm{L}$

$0 \longdiv { 1 6 }$

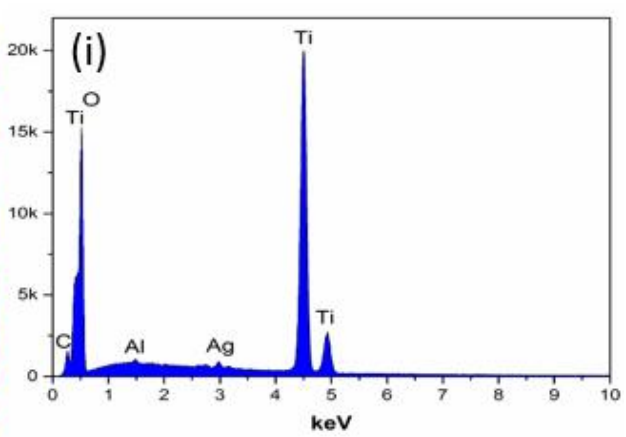

Fig. 2. SEM micrographs of different magnifications (a -c); Elemental mappings (d-h): (d) total mapping, (e-h) $\mathrm{C}, \mathrm{O}, \mathrm{Ti}$, and Ag mappings; and (i) EDX microanalysis of (5\% w/w) $\mathrm{Ag}_{2} \mathrm{O} / \mathrm{P}-25$ selected and as-prepared photocatalyst. 

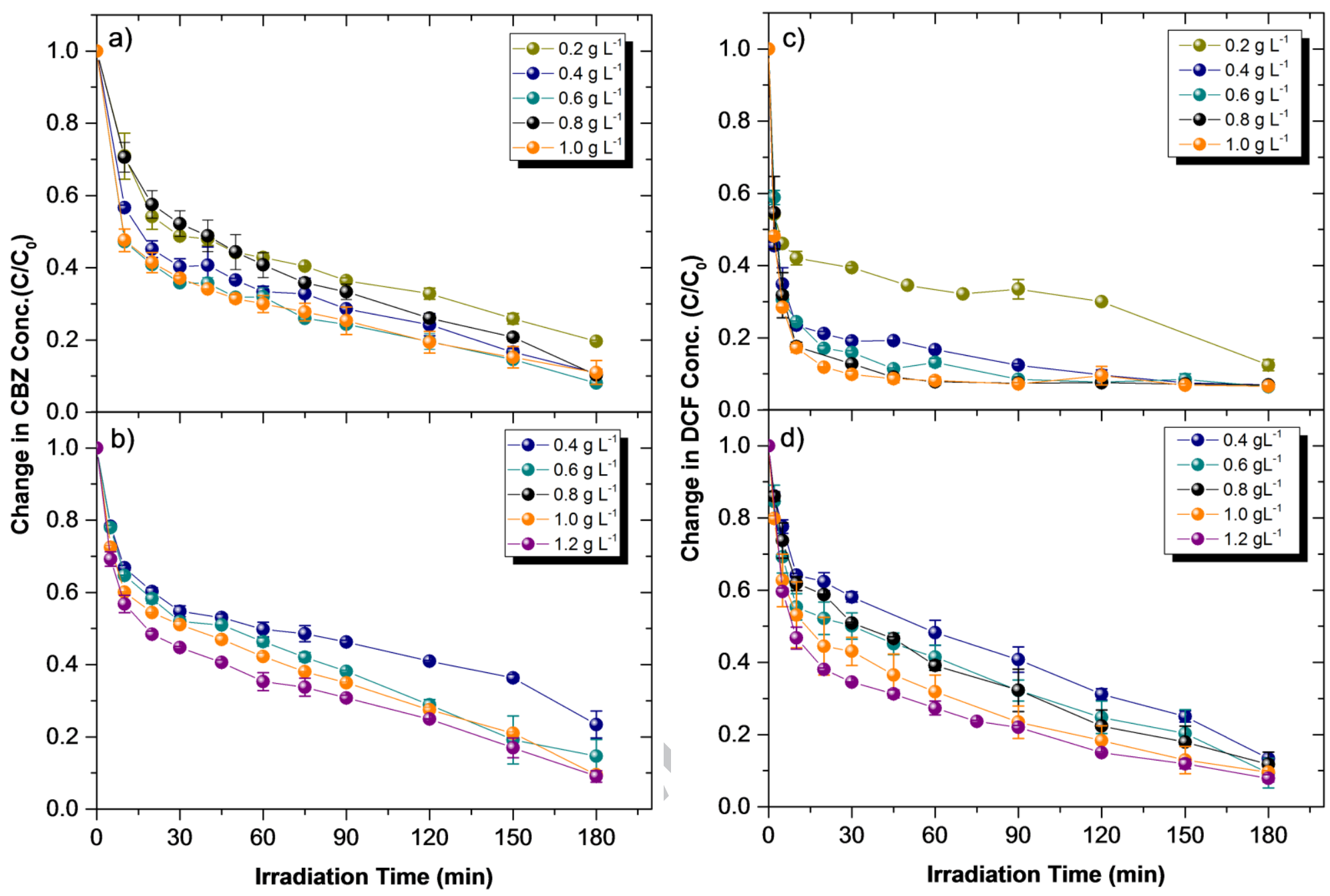

Fig. 3. Effect of catalyst dosing and water matrix on photocatalytic degradation of (a) CBZ in DW, (b) CBZ in RME; and (c) DCF in DW, and (d) DCF in RME. (Operating conditions: [CBZ $]_{0}=[\mathrm{DCF}]_{0}=20 \mathrm{mg} \mathrm{L}^{-1} ; \mathrm{pH}=5-7 ;[5 \%$ $\left.\mathrm{Ag}_{2} \mathrm{O} / \mathrm{P}-25\right]=0.2-1.0 \mathrm{~g} \mathrm{~L}^{-1}$ for DW matrix and $0.4-1.2 \mathrm{~g} \mathrm{~L}^{-1}$ for RME matrix; Temperature $=21 \pm 2{ }^{\circ} \mathrm{C}$ ) 


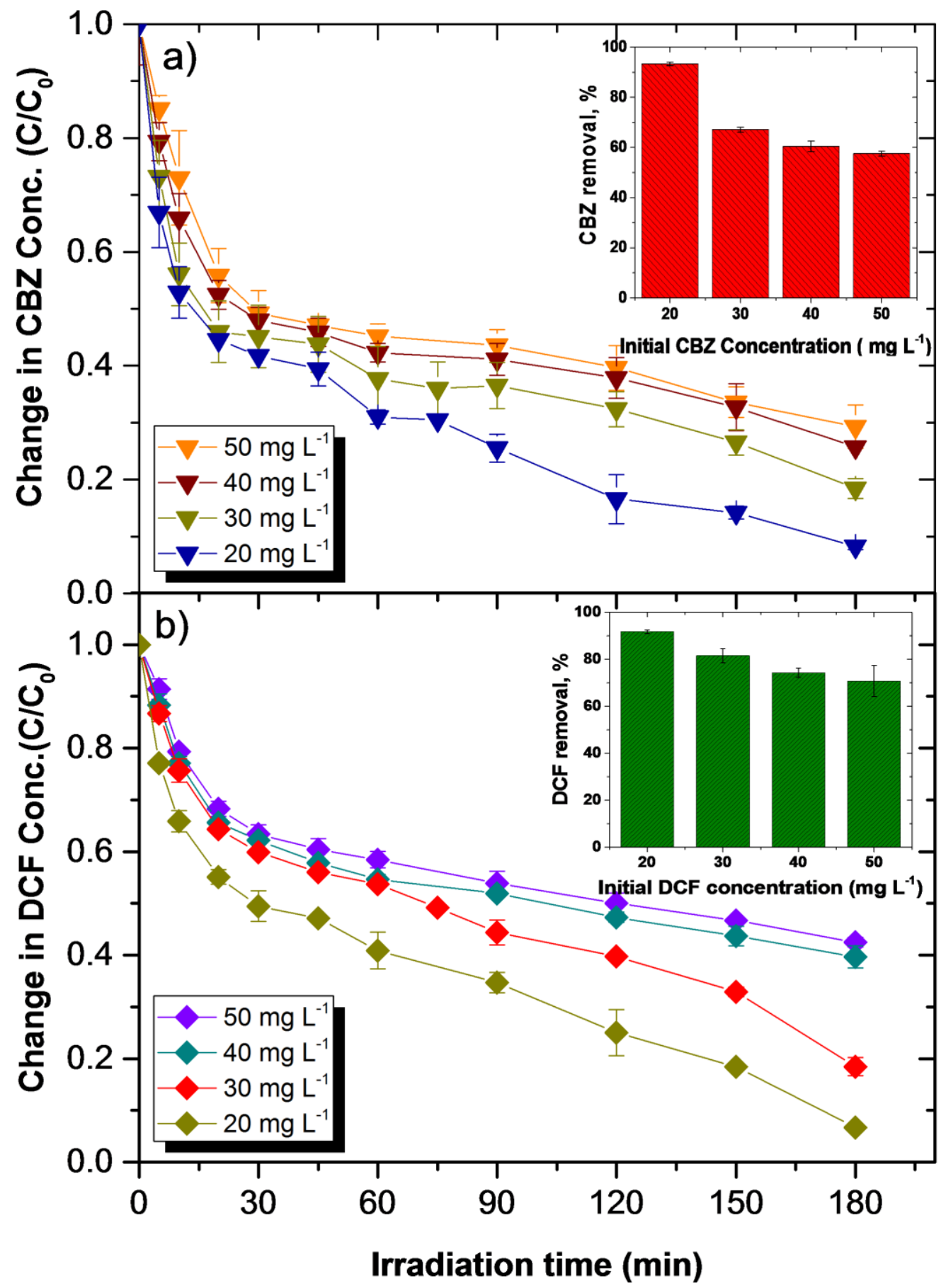

Fig 4. Effect of initial substrate concentration in photocatalytic degradation of (a) CBZ, and (b) DCF. (Operating conditions: All are RME matrix; [5\% $\left.\mathrm{Ag}_{2} \mathrm{O} / \mathrm{P}-25\right]=0.8 \mathrm{~g} \mathrm{~L}^{-1}$ for CBZ; and $0.6 \mathrm{~g} \mathrm{~L}^{-1}$ for DCF). Removal percentages of CBZ and DCF versus initial concentrations are shown in insets of (a), and (b), respectively. 


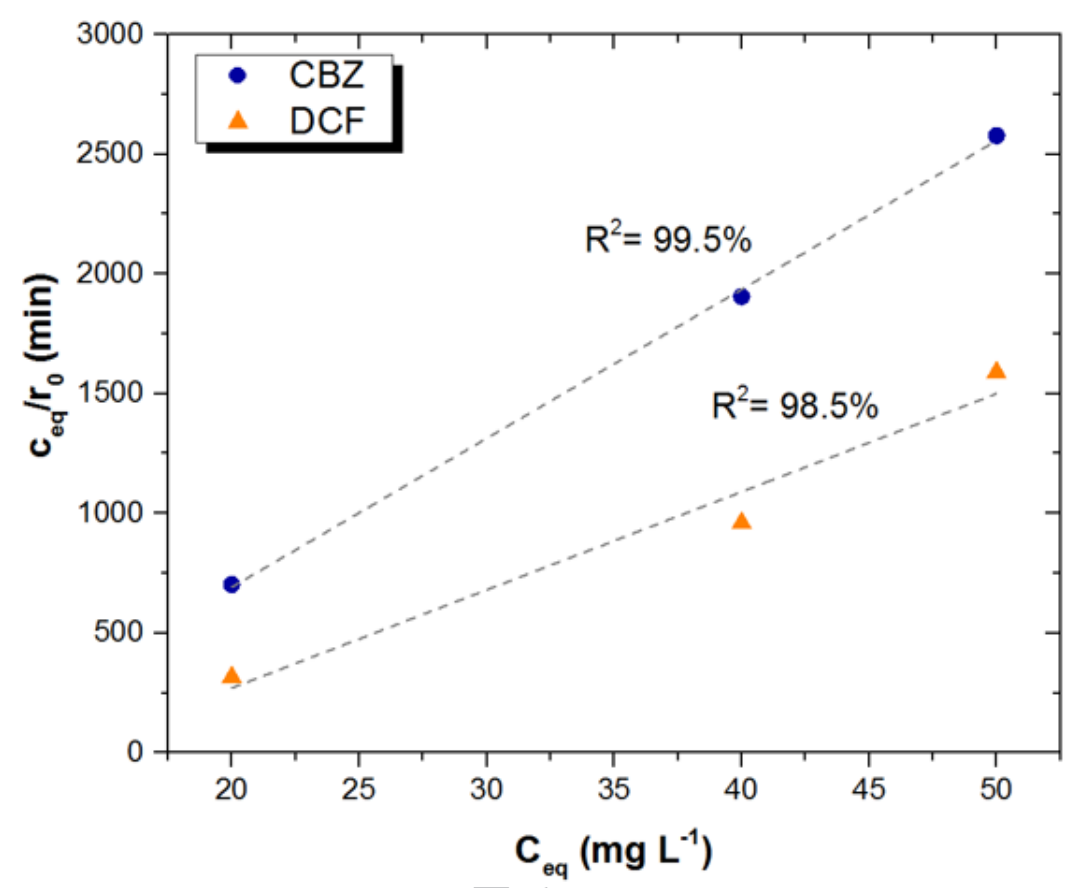

Fig. 5. Fitting of L-H model for photocatalytic degradation kinetics of CBZ and DCF. (Operating conditions: RME solution matrix, $\left.\left[5 \% \mathrm{Ag}_{2} \mathrm{O} / \mathrm{P}-25\right)\right]_{0}=0.8 \mathrm{~g} \mathrm{~L}^{-1}$ for $\mathrm{CBZ}$, and $0.6 \mathrm{~g} \mathrm{~L}^{-1}$ for DCF). Plot of Eq.1. 


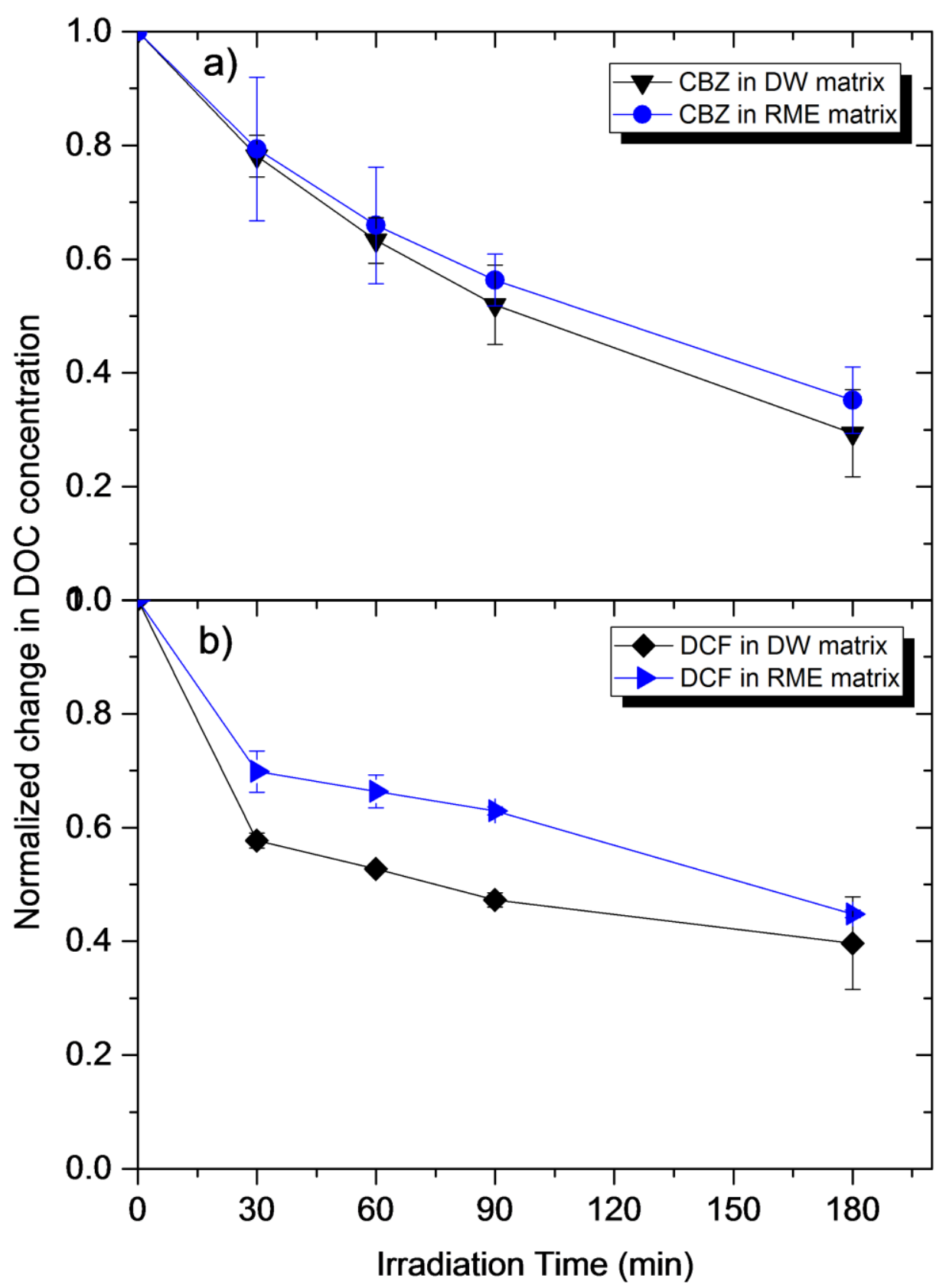

Fig. 6. Mineralization during photocatalytic degradation of (a) CBZ, and (b) DCF in two solution matrices. (Operating conditions: $\left[5 \% \mathrm{Ag}_{2} \mathrm{O} / \mathrm{P}-25\right]=0.4 \mathrm{~g} \mathrm{~L}^{-1}$ in DW matrix for both CBZ and DCF; and 0.8 $\mathrm{g} \mathrm{L}^{-1}$ and $0.6 \mathrm{~g} \mathrm{~L}^{-1}$ in RME matrix for CBZ and DCF, respectively) 


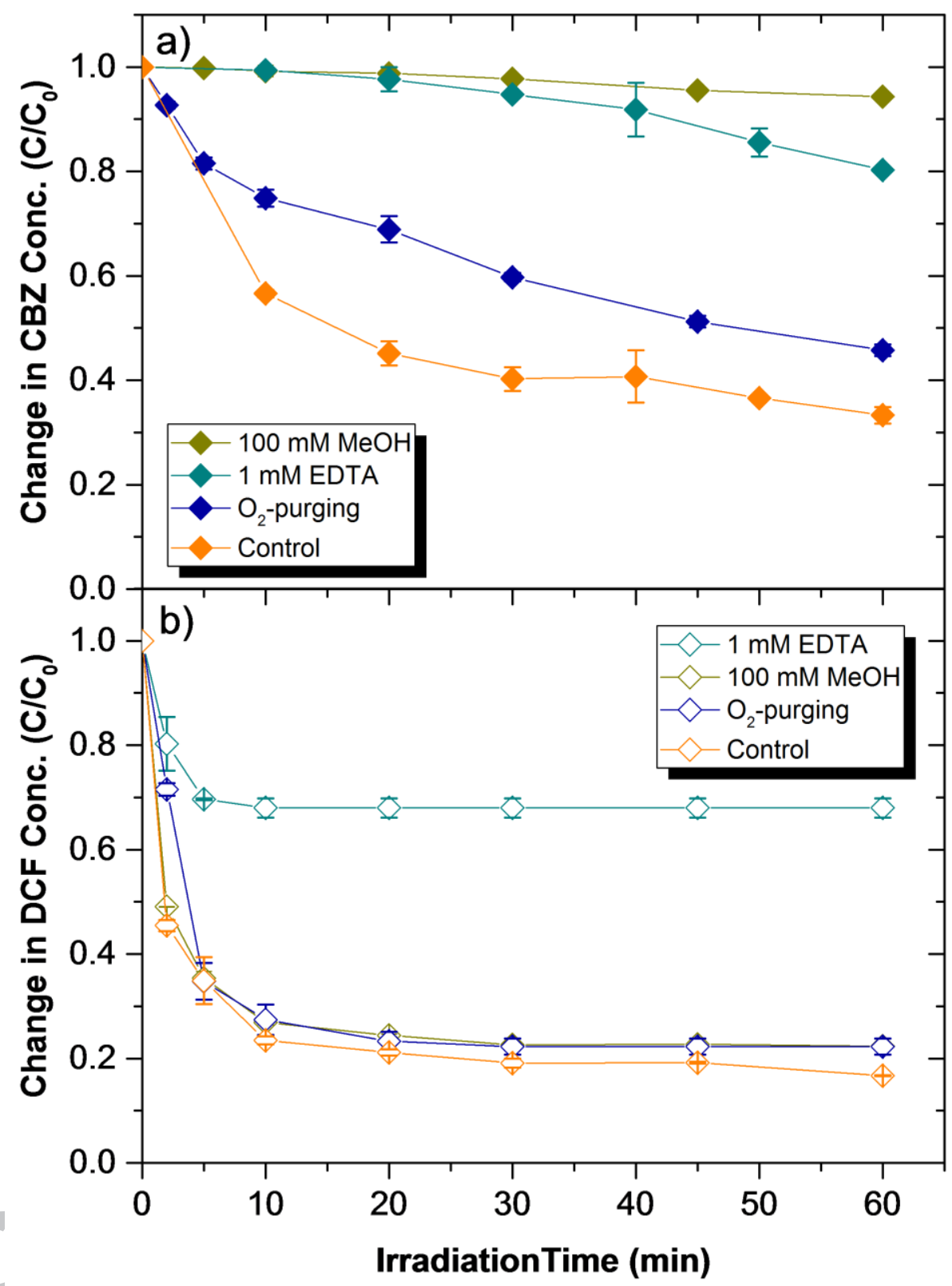

Fig. 7. Trap experiments to assess the role of reactive species during the photocatalytic degradation of (a) CBZ, and (b) DCF. (Operating conditions: [CBZ $]_{0}=[\mathrm{DCF}]_{0}=20 \mathrm{mg} \mathrm{L}^{-1}$; [5 $\left.\left.\% \mathrm{Ag}_{2} \mathrm{O} / \mathrm{P}-25\right]=0.4 \mathrm{~g} \mathrm{~L}^{-1}\right)$ 

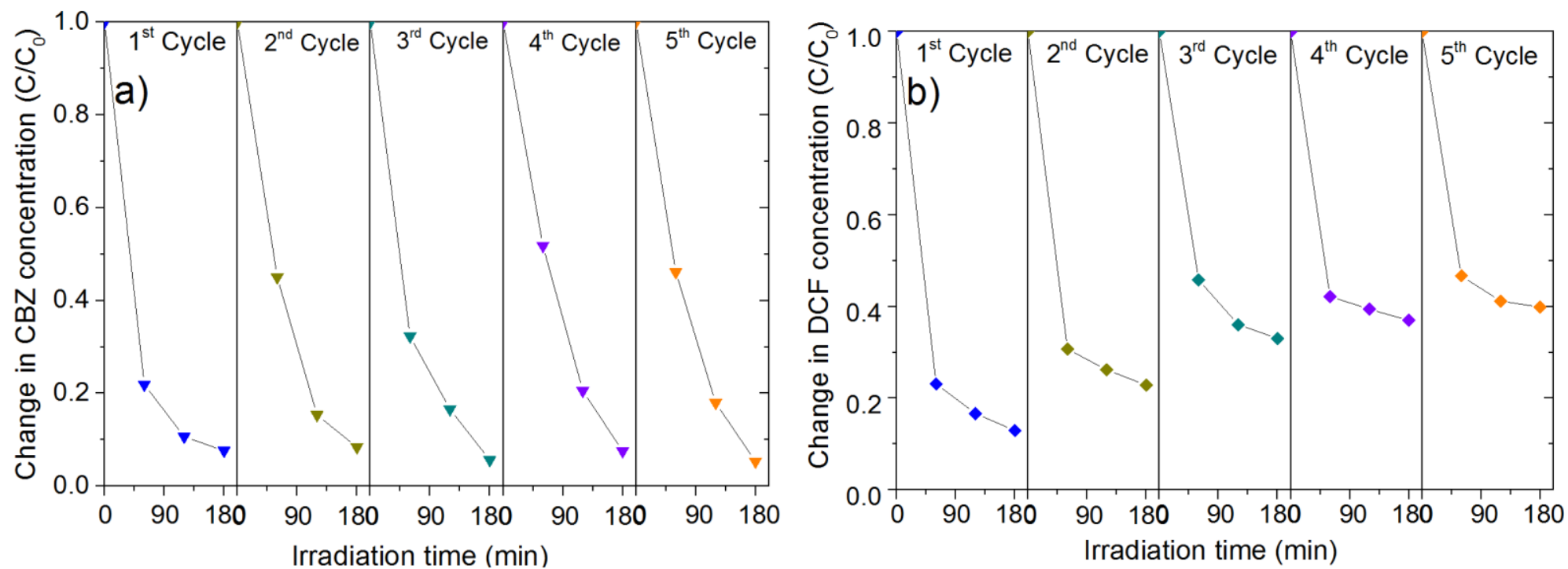

Fig. 8. Cyclic experiments in the photocatalytic degradation of (a) CBZ, and (b) DCF over $5 \% \mathrm{Ag}_{2} \mathrm{O} / \mathrm{P}-25$. 


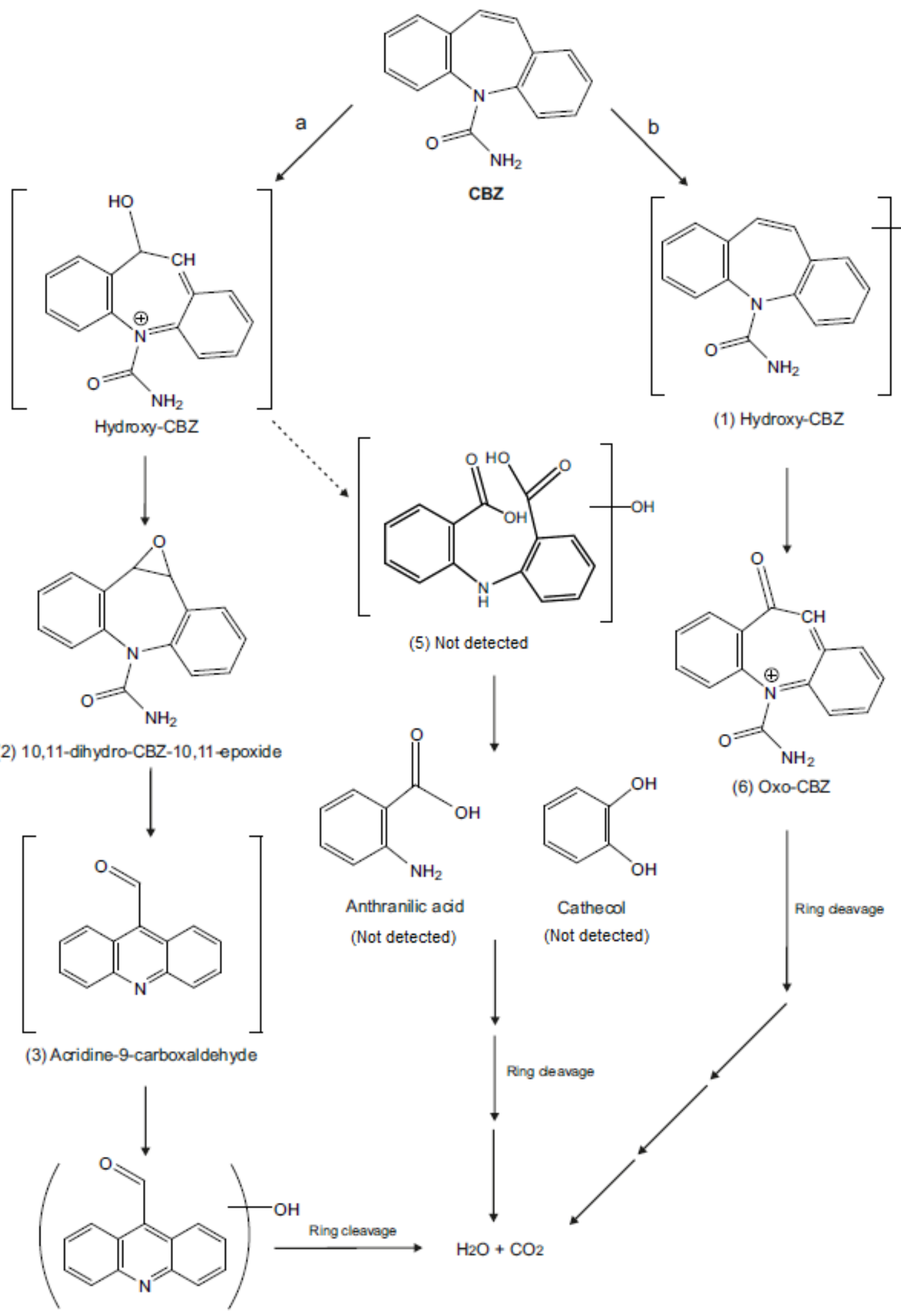

(4) Hydroxyacridine-9-carboxaldehyde

Fig. 9. Proposed photodegradation pathway of $\mathrm{CBZ}$ by $\mathrm{Ag}_{2} \mathrm{O} / \mathrm{P}-25$ under UV light irradiation. $[\mathrm{CBZ}]_{0}=20 \mathrm{mg} \mathrm{L}^{-1}$, Catalyst dosage $=0.4 \mathrm{~g} \mathrm{~L}^{-1}$. 


\section{Table 1}

The physico-chemical properties of target PhACs in this study.

\begin{tabular}{cccc}
\hline Compound/ formula & Therapeutic Use & $\begin{array}{c}\text { Molecular Weight } \\
\left(\mathrm{g} \mathrm{mol}^{-1}\right)\end{array}$ & $\begin{array}{c}\text { Water Solubility } \\
\left(\mathrm{mg} \mathrm{L}^{-1}, 20{ }^{\circ} \mathrm{C}\right)\end{array}$ \\
$\begin{array}{c}\text { Carbamazepine } \\
\left(\mathrm{C}_{15} \mathrm{H}_{12} \mathrm{~N}_{2} \mathrm{O}\right)\end{array}$ & $\begin{array}{c}\text { Antiepileptic, } \\
\text { anticonvulsant drug }\end{array}$ & 236.27 \\
$\begin{array}{c}\text { Diclofenac sodium } \\
\left(\mathrm{C}_{14} \mathrm{H}_{10} \mathrm{C}_{12} \mathrm{NNaO}_{2}\right)\end{array}$ & $\begin{array}{c}\text { Non-steroidal anti- } \\
\text { inflammatory and } \\
\text { analgesics drug }\end{array}$ & 318.13 & \\
\hline
\end{tabular}

${ }^{*}[47]$

[47] J. Deng, Y. Shao, N. Gao, S. Xia, C. Tan, S. Zhou, X. Hu, Degradation of the antiepileptic drug carbamazepine upon different UV-based advanced oxidation processes in water, Chem. Eng. J. 222 (2013) 150-158. doi:10.1016/j.cej.2013.02.045. 


\section{Table 2}

Removal rates $(\% \pm \mathrm{SD})$ of CBZ and DCF under the varying catalyst dosages and the extent of mineralization (\%) in two different water matrices.

\begin{tabular}{|c|c|c|c|c|}
\hline $\begin{array}{l}\text { Solution } \\
\text { Matrices }\end{array}$ & Target Pollutants & $\begin{array}{l}\text { Catalyst concentration } \\
\qquad\left(\mathrm{g} \mathrm{L}^{-1}\right)\end{array}$ & $\begin{array}{c}\text { Removal efficiency } \\
\text { (\%) }\end{array}$ & $\begin{array}{c}\text { Mineralization } \\
(\%)\end{array}$ \\
\hline \multirow{2}{*}{ DW } & CBZ & $\begin{array}{l}0.2 \\
0.4 \\
0.6 \\
0.8 \\
1.0\end{array}$ & $\begin{array}{l}80.40 \pm 0.5 \\
89.10 \pm 1.5 \\
88.60 \pm 1.4 \\
91.70 \pm 1.5 \\
89.02 \pm 4.7\end{array}$ & 67.90 \\
\hline & DCF & $\begin{array}{l}0.2 \\
0.4 \\
0.6 \\
0.8 \\
1.0\end{array}$ & $\begin{array}{l}87.60 \pm 2.2 \\
93.50 \pm 0.1 \\
93.60 \pm 0.1 \\
93.04 \pm 0.1 \\
93.40 \pm 0.3\end{array}$ & 64.80 \\
\hline \multirow{2}{*}{ RME } & CBZ & $\begin{array}{l}0.4 \\
0.6 \\
0.8 \\
1.0 \\
1.2\end{array}$ & $\begin{array}{l}76.60 \pm 5.2 \\
85.40 \pm 6.5 \\
89.74 \pm 0.4 \\
90.50 \pm 0.4 \\
90.95 \pm 2.3\end{array}$ & 60.30 \\
\hline & DCF & $\begin{array}{l}0.4 \\
0.6 \\
0.8 \\
1.0 \\
1.2\end{array}$ & $\begin{array}{c}86.60 \pm 0.3 \\
90.70 \pm 4.5 \\
88.30 \pm 3.4 \\
90.40 \pm 0.40 \\
92.10 \pm 1.10\end{array}$ & 55.20 \\
\hline
\end{tabular}




\section{Highlights:}

- $\quad 5 \% \mathrm{Ag}_{2} \mathrm{O} / \mathrm{P}-25$ photocatalyst was selected, prepared, and characterized

- Photodegradation of CBZ and DCF was optimized and assessed in different matrices

- Substantial improvement in PhACs removal and mineralization

- Photo-generated $h^{+}$and $\bullet \mathrm{OH}$ were dominant oxidation species

- Selected photocatalyst enabled several reusability cycles 